\title{
PREFERENCE FOR MODE OF DELIVERY IN A LOW RISK POPULATION IN CAPE TOWN, SOUTH AFRICA
}

\author{
By \\ Dr Nadia Naudé \\ NDXNAD007 \\ SUBMITTED TO THE UNIVERSITY OF CAPE TOWN \\ In fulfilment of the requirements for the degree \\ MMed in Obstetrics and Gynaecology \\ Faculty of Health Sciences \\ UNIVERSITY OF CAPE TOWN
}

Date of submission: 10 October 2014

Supervisors:

Dr Tracey Anne Horak

Professor Susan Fawcus

Department of Obstetrics and Gynaecology

University of Cape Town 
The copyright of this thesis vests in the author. No quotation from it or information derived from it is to be published without full acknowledgement of the source. The thesis is to be used for private study or noncommercial research purposes only.

Published by the University of Cape Town (UCT) in terms of the non-exclusive license granted to UCT by the author. 


\section{DECLARATION}

I, Nadia Naudé, hereby declare that the work on which this dissertation is based is my original work (except where acknowledgements indicate otherwise) and that neither the whole work nor any part of it has been, is being, or is to be submitted for another degree in this or any other university.

I empower the university to reproduce for the purpose of research either the whole or any portion of the contents in any manner whatsoever.

Signature: $\quad$ Signed by candidate

Date at Cape Town: 10 October 2014 


\section{ACKNOWLEDGEMENTS}

I would like to thank my colleagues for their help and support during the preparation of this dissertation, especially:

DR. TRACEY ANNE HORAK

MBChB, FCOG (SA), MMed (UCT)

Senior Specialist: Mowbray Maternity Hospital, for supervising this project

PROF. SUSAN FAWCUS

MA, MB.BS, FRCOG

Head of Obstetrics: Mowbray Maternity Hospital, for co-supervising this project

Ms KATYA MAUFF

Ms USHMA GALAL

STATISTICAL CONSULTANTS

Department of Statistical Sciences

University of Cape Town, for help with the statistical analysis

DR. GREGORY PETRO

MBChB, FCOG (SA), CBAM (DMS)

Head of Obstetrics and Gynaecology: New Somerset Hospital, for help with preparation of the manuscript 


\section{Table of Contents}

DECLARATION 2

ACKNOWLEDGEMENTS 3

LIST OF ABBREVIATIONS

LIST OF FIGURES

$\begin{array}{ll}\text { LIST OF TABLES } & 7\end{array}$

$\begin{array}{ll}\text { ABSTRACT } & 8\end{array}$

$\begin{array}{lr}\text { Introduction } & 8\end{array}$

Aims and Objectives $\quad 8$

Methodology 8

Results 9

Conclusion 9

$\begin{array}{ll}\text { INTRODUCTION } & 11\end{array}$

LITERATURE REVIEW

$\begin{array}{ll}\text { AIMS AND OBJECTIVES } & 31\end{array}$

METHODS 32

Study Design $\quad 32$

Study Setting $\quad 32$

Study Population $\quad 33$

Study Methodology 33

Data collection $\quad 35$

$\begin{array}{ll}\text { Sample size } & 35\end{array}$

Statistical Analysis $\quad 36$

Ethical Considerations $\quad 36$

$\begin{array}{ll}\text { RESULTS } & 38\end{array}$

DISCUSSION $\quad 54$

Preference for mode of delivery $\quad 54$

Strengths and limitations $\quad 62$

Implications for Further Research 63

Recommendations 64

$\begin{array}{ll}\text { CONCLUSION } & 66\end{array}$

REFERENCES $\quad 67$

$\begin{array}{ll}\text { Appendix } & 76\end{array}$

$\begin{array}{ll}\text { Appendix A - Questionnaire } & 77\end{array}$

Appendix B - Patient information leaflet and consent form 85 


\section{LIST OF ABBREVIATIONS}

CDMR

CI

CPD

HAART

$\mathrm{MMH}$

MOU

MTCT

NCHS

NICE

NICU

NNTT

$\mathrm{RR}$

USAID

US

VBAC

WHO
Caesarean Delivery on Maternal Request

Confidence Interval

Cephalo-Pelvic Disproportion

Highly Active Antiretroviral Therapy

Mowbray Maternity Hospital

Midwife Obstetric Unit

Mother to Child transmission

National Centre for Health Statistics

National Institute for Health and Clinical

Excellence in the United Kingdom

Neonatal Intensive Care Unit

Number Needed to Treat

Relative Risk

United States Agency for International

Development

United States

Vaginal Birth After Caesarean Section

World Health Organization 


\section{LIST OF FIGURES}

Figure 1. Flow chart of recruitment process

Figure 2. Distribution of primigravidas and multigravidas at Gugulethu MOU and Mitchell's Plain MOU

Figure 3. Women's Preference for mode of delivery

Figure 4. Comparison of Preference for mode of delivery between MOU's

Figure 5. Comparison of Preference for Mode of delivery between Primigravidas and Multigravidas

Figure 6. Comparison of preferred mode of delivery between the different age groups

Figure 7. Comparison of preferred mode of delivery between the two ethnic groups in the study

Figure 8. Comparison of preferred mode of delivery and different education levels

Figure 9. Comparison of preferred mode of delivery and HIV status

Figure 10. Women's right to request a caesarean section 


\section{LIST OF TABLES}

Table 1. Demographic characteristics of study participants

Table 2. Socio-economic characteristics of study population

Table 3. Reasons behind women's preference for vaginal delivery

Table 4. Reasons for preferring Caesarean Section

Table 5. Women's knowledge about caesarean section indications 


\section{ABSTRACT}

\section{Introduction}

Over the past few decades there has been an increase in caesarean section rates that has been well documented in many developed countries. The impact of this cannot be ignored as several studies have shown higher risks of maternal morbidity and mortality with caesarean section as compared to vaginal births. The reasons behind it are complex, with maternal request frequently being cited as a major contributor. A growing body of evidence shows that relatively few women would actually prefer to deliver by caesarean section. Caesarean section on request is not routinely offered in the public health care sector in South Africa, and is therefore unlikely to contribute significantly to the overall caesarean section rate. In the South African context very few studies examining women's preference for mode of delivery exist.

\section{Aims and Objectives}

The primary aim of our study was to determine women's preference for mode of delivery during the third trimester of pregnancy in a low risk population.

The secondary outcome was to describe the major reasons for their preferred mode of delivery.

\section{Methodology}

We conducted a cross-sectional descriptive study of pregnant women attending antenatal care at two midwife obstetric units (MOUs) in Gugulethu and Mitchell's Plain in the Western Cape. Women were recruited during the third trimester of pregnancy and women over the age of 18 , with a singleton low risk pregnancy, planning to deliver at the MOU, were eligible for inclusion. Two trained interviewers conducted an interview-based questionnaire regarding women's 
preference for mode of delivery. Data on demographic and socio-economic characteristics were also collected. We also described the major reasons behind women's preferred mode of delivery.

\section{Results}

Of the 195 women that participated in our study, 160 (82.1\%) indicated a preference for vaginal delivery. This compared to only 5 (2.6\%) of the study participants who preferred a caesarean delivery, and 30 women (15.4\%) who were unsure about their preferred mode of delivery.

Of the group preferring caesarean section, all five women (100\%) cited 'fear of vaginal birth' as the major reason for preferring a caesarean section.

Of the 195 women that participated in our study, 106 (54.4\%) did not believe that women should be given the right to request a caesarean section in the absence of a medical indication, 14 women were unsure (7.2\%) and 75 of them believe that women should have the right to request a caesarean (38.5\%).

\section{Conclusion}

The need for maternity services that are more women-centred has arisen, with an increasing emphasis on maternal choice and birth satisfaction. Our study contributed to the mounting body of evidence that the majority of women prefer to have a vaginal delivery. In the small group preferring caesarean section, 'fear of vaginal birth' was the major reason behind their preference. There were a considerable number of women in our study population who were unsure about their preference. This indicates a need for improved antenatal education. Knowledge about women's preference and the reasons they regard as important will aid health care providers in counselling patients appropriately regarding the 
risks and benefits of both delivery methods and thereby enable women to make an informed decision about their preferred mode of delivery. 


\section{INTRODUCTION}

Over the past three decades there has been a well-documented increase in the caesarean section rate in many countries worldwide. In the United States (US), for instance, caesarean section rates have increased steadily from $21 \%$ in 1996 to $32 \%$ in 2007. ${ }^{1}$ The primary caesarean rate (percentage of caesarean deliveries for first births) in the US has risen by $23 \%$ between 1996 and $2002 .{ }^{2}$

Although the distribution of the worldwide caesarean-rates differs, for instance, with Latin America at $29.2 \%$ and Africa $3.5 \%$ in $2002^{3}$, the rates do not appear to be stabilizing, as a 2005 survey conducted by the World Health Organization (WHO) in Latin America showed an average caesarean rate of $33 \%{ }^{4}$

The implications of rising caesarean rates cannot be ignored, as several studies have shown higher risks of maternal morbidity and mortality with caesarean section as compared to vaginal birth., 24, 25 Belizán et al (2006) demonstrated a higher risk of hysterectomy, urethral and vesical injury, abdominal pain, neonatal respiratory morbidity, fetal death, placenta praevia and uterine rupture in future pregnancies, in women undergoing caesarean delivery as compared to vaginal birth. ${ }^{5}$ The National Institute for Health and Clinical Excellence in the United Kingdom (NICE) guidelines on Caesarean section showed an increased risk of longer hospital stay, hysterectomy secondary to postpartum haemorrhage, and cardiac arrest in planned caesarean section, as well as an increased risk of babies being admitted to the neonatal intensive care unit (NICU). ${ }^{6}$ Indeed, the WHO recommended in 1985 that no more than $15 \%$ of births should be delivered by caesarean section. ${ }^{7}$

A variety of complex reasons have been cited to explain the rising trends in caesarean section rates. For example, as progress in the development of surgical and anaesthetic techniques is made, patients and health care providers have come to perceive caesarean section as a much safer procedure. ${ }^{4}$ Rising caesarean section rates could also be driven by the expansion of medical indications. The National Sentinel Caesarean Section Audit by the Royal College 
of Obstetricians and Gynaecologists showed the main indications for caesarean section in England and Wales to be fetal distress (22\%), failure to progress (20 $\%)$, previous caesarean section (14\%) and breech presentation (11\%). ${ }^{8}$

Another explanation for the increase in caesarean section rates has been the sharp decline in vaginal births after previous caesarean (VBAC). In the US, for instance, the VBAC rate has fallen by $55 \%$ since $1996 .^{2}$ Increased malpractice litigation against medical practitioners has been proposed as another important factor behind the increasing rates, especially in private practice. A South African study conducted by Chalmers et al (1992) has shown that $75.3 \%$ of private sector doctors cited "fear of litigation" as one of the main reasons for performing caesarean section, compared to $21.2 \%$ of doctors working in state-run hospitals. ${ }^{9}$

Interestingly, maternal request for caesarean section in the absence of medical indication is increasingly perceived as the reason for the increase in caesarean section rates. A significant number of studies, however, do not support this. A study conducted in the US by Pevzner et al (2008) showed that only $5 \%$ of pregnant patients who participated in the study thought that caesarean delivery on maternal request was a good idea, and only $7 \%$ would prefer to deliver by caesarean section. ${ }^{10}$ A Swedish questionnaire-based study with 3013 pregnant participants by Hildingsson et al (2002) found that $8.2 \%$ of the study participants preferred caesarean delivery. ${ }^{11}$

Since caesarean section on request is not routinely offered in the South African public health care sector, it is unlikely that this factor significantly contributes to the rising caesarean section rate in public sector or 'state' hospitals. In a critical review of the literature, McCourt et al (2007) concluded that only a minority of women in fact, prefer caesarean section, and that this group of women "have reasons they regard as clinically or psychologically important". ${ }^{12}$

Maternal choice and satisfaction after birth has become increasingly important in the changing world of obstetrics. This is reflected in the NICE guidelines on 
caesarean section, which state that: "Pregnant women should be offered evidence-based information and support to enable them to make informed decisions about childbirth. Addressing women's views and concerns should be recognised as being integral to the decision-making process." 6 In the United Kingdom, two publications, the 'Changing Childbirth' report and the 'Audit Commission Report', emphasized that maternity services needed to become more women-centred and had to encourage women to choose the type of care they preferred. ${ }^{13}$

There is limited data on South African women's preference for mode of delivery. This is despite a definite shift in South African obstetric practice towards patients being more centrally involved in decision-making regarding their care, with satisfaction following childbirth becoming increasingly important. The rationale behind this study, therefore, is to gain better insight into women living in Cape Town's preference for mode of delivery. Conducting this study would also give us the opportunity to examine the reasons behind women's preference and the factors influencing their decision-making, thereby contributing to the broader discourse on this topic. 


\section{LITERATURE REVIEW}

\section{Caesarean Section Rate}

Over the past few decades, there has been a well-documented increase in the caesarean section rates in many countries. A study by Bétran et al (2002) analysing data from 125 countries, showed a global caesarean section rate of 15 $\%$. They also showed a big discrepancy between the rates in developed and developing countries, with Latin America showing the highest rate (29.2\%) and Africa the lowest rate (3.5\%). South Africa had the highest rate in Africa (15.4 $\%)^{3}$

The Annual Summary of Vital Statistics in the United States 2002, reported caesarean delivery rates of $26.1 \%$. This represents an increase of $7 \%$ from 2001 and a $26 \%$ increase since $1996^{2}$ These rates do not appear to be stabilizing. A report published by the National Centre for Health Statistics (NCHS) in 2010, showed a 53 \% rise in caesarean rates from 1996 to 2007, reaching $32 \%$. This was the highest caesarean section rate that was ever reported in the US. ${ }^{1}$

Similar high rates were shown for Latin America in a 2005 WHO global survey on Maternal and Perinatal Health, which looked at 24 geographic regions in eight countries. The median caesarean section rates were $33 \%$. Even higher rates of $51 \%$ were noted in some private hospitals. ${ }^{4}$ In South Korea, a National Fertility and Family Health Survey in 2000, showed caesarean section rates of $37.7 \%$. This is a nine-fold increase since $1982 .{ }^{14}$

The National Sentinel Caesarean Section Audit published in 2001, reported slightly lower caesarean section rates in England and Wales of $21.5 \%$. This signifies an annual increase of $1 \%$ over the past decade. Interestingly, the Nordic countries (Norway, Finland, Sweden and Denmark) showed a similar increase in rates until 1990, but subsequently, their rates stabilized at $12-14 \%{ }^{8}$ 
South African caesarean section rates have also been rising. The WHO reported in 1998 that $16 \%$ of all births in South Africa were by caesarean section. ${ }^{15}$ The 2012/13 South African Health Review (SAHR) described caesarean section rates in 2009 of $20.3 \%$. By 2011 these rates had risen to $22.7 \%{ }^{16}$ In the South African private sector, significantly higher rates are reported in some areas, compared to the state. This is illustrated by Tshibangu et al (2002) who found caesarean section rates for six private hospitals in Pretoria to be as high as 57.43 \%. ${ }^{17}$ These high rates in the private sector have been confirmed in the 2012/13 SAHR report that showed caesarean rates of $68 \%$ in 2009.16

The consequences of rising caesarean section rates cannot be ignored. Several studies have postulated that there is no benefit associated with higher rates, but rather that they may lead to an increase in maternal morbidity and mortality. ${ }^{4,24}$, 25 The 2005 WHO global survey on Maternal and Perinatal Health in Latin America showed a positive association between the rate of caesarean delivery and the need for postpartum antibiotics, as well as an overall adverse effect on maternal morbidity and mortality. ${ }^{4}$ Furthermore, a rise in the primary caesarean section rate will inevitably impact on future pregnancies, and place a financial burden on health structures. ${ }^{8}$

What the ideal caesarean rate should be, has been the subject of extensive ongoing debate. The notion of an 'ideal rate' stems from the recommendation by the WHO in 1985, that no more than $15 \%$ of births should be delivered by caesarean section. ${ }^{7}$ This figure was modelled on the caesarean section rates of countries, who at the time, had the lowest maternal and perinatal mortality rates. ${ }^{18} \mathrm{~A}$ few studies have criticized the use of a specific value to define the 'optimal' caesarean section rate. The State-of-the-Science Conference on Caesarean Delivery for Maternal Request in 2006 discouraged the 'ideal rate', stating that 'optimum caesarean delivery rates will vary over time and across different populations'. ${ }^{19}$ A similar statement was made by Robson (2001) who suggested that caesarean section rates should be determined by maternal and fetal outcome. He further proposed that this rate should be determined locally 
and that rates should vary between units. ${ }^{13}$ This proposal would make sense in the South African context of a tiered referral system, where, for instance, the caesarean section rate at a tertiary institution would be expected to be higher than that of the district hospital that refers complicated patients.

\section{History}

The first reference to caesarean section in ancient and medieval history can be found in Hindu, Greek, Egyptian and Roman legends. ${ }^{20}$ The term 'caesarean' was thought to have originated from the birth of Julius Caesar. This is unlikely however, as his mother, Aurelia, survived her son at a time when this procedure was only performed when the woman was dead or dying. ${ }^{21}$

One of the first citations to caesarean section where the mother and fetus apparently survived was in 1500. Jacob Nufer, a pig farmer in Switzerland, allegedly operated on his wife after a prolonged labour. ${ }^{22}$ The De Corporis Humani Fabrica was published in 1543 by Andreas Vesalius documenting the female and abdominal anatomy. This provided the basis for operative obstetrics in the $18^{\text {th }}$ and $19^{\text {th }}$ century. ${ }^{21}$

Dr James Miranda Stuart Barry reportedly did the first successful caesarean section around 1815. She was serving in the British army as a physician, disguised as a man. ${ }^{20}$ A further development happened in 1846, when William Morton gave a patient ether for sedation, hence leading the way in the development of anaesthesia. James Young Simpson introduced chloroform as a method of inducing unconsciousness in 1847. This was further popularized in 1853 and 1857 by Queen Victoria, who reportedly used chloroform during the birth of two of her children. ${ }^{21}$

In 1876, Eduardo Porro encouraged the idea of hysterectomy at the time of caesarean section to stop bleeding. Richardson first performed this procedure successfully in 1881 . This lead to a major improvement in maternal mortality. 
Adolf Kehrer and Max Sänger made further advances in 1882, by the use of silver wires to close the uterus. Semmelweis introduced hand washing in 1847 and paved the way for major improvement in asepsis. Following this, Joseph Lister introduced antisepsis by using carbolic acid spray in $1867 .{ }^{21}$ All of these advances and developments, together with the benefit of penicillin and blood transfusion stemming from the Second World War, lead to a significant decrease in maternal mortality. At the beginning of the nineteenth century, maternal mortality following caesarean section was between 65 and $75 \%$. By the turn of the century these mortality rates had decreased to 5-10 \% ${ }^{23}$

Caesarean section has evolved from an operation attempting to save the soul of the fetus whose mother was dead, to a frequently performed procedure in which the mother not only expects to survive, but also expects her baby to survive..$^{20}$

\section{Impact of Caesarean Section Rates on Morbidity and Mortality}

\section{Maternal}

There is a growing concern that rising caesarean section rates are associated with an increase in maternal morbidity and mortality, and that the risks may outweigh the benefits to the mother. This was confirmed by Villar et al (2007) who conducted a prospective cohort study analysing data from 97095 deliveries (33.7\% were caesarean deliveries). Caesarean delivery was associated with a significantly higher risk of morbidity and mortality when compared to vaginal delivery. Caesarean delivery was associated with a three to five times higher risk of maternal demise, a four times higher risk of hysterectomy and carried twice the risk of being admitted to an intensive care unit (ICU). ${ }^{24}$ These findings are corroborated by the 2004-2008 WHO Global Survey on Maternal and Perinatal Health, which showed an increase in adverse short-term maternal outcomes with any mode of delivery other than spontaneous vaginal delivery. An increased risk of death, ICU admission, hysterectomy and blood transfusion was shown. Importantly, these risks were shown to rise considerably when caesarean section was performed with no medical indication. ${ }^{25}$ Another publication demonstrating the increased risk of adverse maternal outcome with 
caesarean delivery as compared to vaginal delivery, is the National Institute for Health and Clinical Excellence in the United Kingdome (NICE) guideline on Caesarean section from November 2011. It reports an increased risk in hysterectomy due to postpartum haemorrhage with a Relative Risk (RR) of 2.31 (95\% CI 1.3 - 4.09), cardiac arrest with a RR of 4,91 (95 \% CI $3.95-6.11$ ) and longer hospital stay, RR 1.58 (95\% CI 1.27 - 2.17). ${ }^{6}$

In stark contrast to the high caesarean section rates noted in developed countries, are the many developing countries in which there is inadequate use of caesarean section. This is illustrated by Betran et al (2007) who found the caesarean section rate to be unevenly distributed worldwide. ${ }^{3}$ Most countries with high maternal mortality rates have low caesarean section rates, with Central African Republic, Burkina Faso, Mali and Nigeria all showing caesarean section rates below $2 \%{ }^{3}$

Afghanistan has a maternal mortality rate estimated at 400 per 100000 live births in Kabul, and an even higher rate in the more remote parts, of 6500 per $100000 .{ }^{26}$ In an attempt to improve these extremely high rates of mortality, the Afghanistan's Ministry of Public health has ordered the development and extension of maternal health services, with the specific aim of addressing the lack of availability and access to caesarean section. ${ }^{26}$

The WHO global survey on Maternal and Perinatal Health in Africa examined statistics from 83439 births that took place in 131 facilities. The caesarean delivery rate for the 7 African countries that participated was $8.8 \%$. Of note, was that only $72.5 \%$ of the included facilities performed caesarean section. High emergency caesarean section rates were associated with poor perinatal outcome. In contrast to this, high elective caesarean section rates were associated with fewer fetal deaths and fresh stillborns. ${ }^{27}$ It is possible that this is due to the fact that in many cases, emergency caesarean section was performed too late to impact on fetal outcome. 
There are also groups of women who might decline delivery by caesarean section, even when medically indicated. A Nigerian study by Aziken et al (2007) showed that $19 \%$ of pregnant women who took part in the study would still decline a caesarean section, even if it meant saving their lives or the lives of their babies. ${ }^{28}$ Some of the reasons behind this cited during focus group discussions, included fear of death and pain, husbands not approving, and caesarean section not being 'culturally accepted'.28 These findings were echoed by Brown et al (2010) who interviewed Somali women who now reside in the US, about their health experiences. Of the participants, $75 \%$ indicated an aversion to caesarean section, citing 'fear of dying' as the main concern. ${ }^{29}$

\section{Neonatal}

The risk-benefit ratio of rising caesarean delivery rates also needs to be considered when regarding neonatal morbidity and mortality. Fogelson et al (2005) evaluated neonatal outcomes in mothers giving birth by elective caesarean section compared to uncomplicated vaginal deliveries. In the elective caesarean section group, they demonstrated a higher risk of admission to an advanced care nursery, $14.5 \%$ vs. $4.1 \%$ in the vaginal delivery group with a RR of 3.58 ( $95 \%$ CI 3.35 - 3.58). An increased risk of transient tachypnoea was also more common in the caesarean section group, $6.0 \%$ vs. $1.7 \%$ with a RR of 3.48 (95 \% CI 3.16 - 3.81). ${ }^{30}$ The NICE guidelines on caesarean section also showed a significantly increased risk of NICU admission for planned caesarean section (13.9\%) as compared to planned vaginal delivery (6.3 \%), RR 2.20 (95 \% CI 1.4 $3.18) \cdot{ }^{6}$

The WHO global survey on Maternal and Perinatal Health in Latin America from 2005 showed that caesarean delivery did not have a beneficial impact on fetal outcome. It demonstrated an increase in fetal demise that was independently associated with caesarean section. Additionally, increased rates of preterm delivery and fetal death were demonstrated when caesarean delivery rates rose above $10 \%{ }^{4}$ 


\section{Risks and Benefits associated with Caesarean Section}

Counselling patients about the risks and possible benefits of caesarean section is important, as it enables patients to make an informed choice about their delivery method. This becomes even more relevant in an era when elective primary caesarean section, and whether it should be offered without medical indication, is a topic of widespread debate. Unfortunately, there are no randomised control trials comparing the short- and long-term consequences of elective caesarean section and vaginal delivery.

There are some studies that suggest an increased risk of anal incontinence following vaginal delivery. ${ }^{31}$ This implies that primary elective caesarean section might have a protective effect on anal continence. A systemic review by Nelson et al (2006) contested this assumption. In this review, fifteen studies were included, examining the effectiveness of caesarean section to prevent anal incontinence. The number needed to treat (NNTT) by caesarean section to avoid one case of faecal incontinence, was 167. The RR for faecal incontinence was 0.91 (95\% CI $0.74-1.14) .{ }^{32}$ The conclusion drawn from this review, was that caesarean section does not prevent anal incontinence, but further randomized control trials are needed to confirm these findings.

The impact of caesarean section and the risks it poses for future pregnancies has to be considered carefully. The NICE guidelines report an increased risk of fetal death (RR 1.6 ; 95 \% CI 1.2 - 2.3), placenta praevia (RR 1.6 ; 95 \% CI 31.1 - 57.2) and uterine rupture in future pregnancies (RR 42.2 ; 95 \% CI 31.1 - 57.2), following caesarean section. ${ }^{6,33}$ Uterine rupture is a rare complication of a planned vaginal birth after a previous caesarean section (VBAC), and the associated morbidity and mortality is considerable. The Green-top guideline on vaginal birth after caesarean estimates the risk of uterine rupture for VBAC to be $22-74 / 10000 .^{34}$

Of all the maternal deaths worldwide, $50.4 \%$ occur in sub-Saharan Africa. ${ }^{35}$ Caesarean section can be a life-saving procedure for mother and baby, as is 
evident by the WHO "Making Pregnancy Safer Programme" in which access to basic emergency obstetric services, as well as caesarean section and blood transfusion are key elements. ${ }^{35}$

Caesarean section does offer some advantages. Elective caesarean section can be used as an additional measure to prevent mother-to-child-transmission (MTCT) of HIV. During the early 1990's, elective caesarean section was shown to halve the risk of MTCT, and these findings were confirmed by a large meta-analysis which showed a $50 \%$ reduced risk associated with elective caesarean section. ${ }^{36}$ Some studies have shown higher complication rates in HIV positive women who underwent caesarean section, with postpartum fever being amongst the most common. ${ }^{37}$ In the era of highly active antiretroviral therapy (HAART), we should consider carefully whether this perceived benefit is still valid. Indeed, the South African Antiretroviral Treatment Guidelines of 2013 state that 'Caesarean sections should be performed for obstetric indications and are not recommended to reduce MTCT', ${ }^{38}$ The NICE guidelines recommend offering a caesarean to HIV positive women who are not on HAART or have a viral load of $400 \mathrm{copies} / \mathrm{ml}$ or more when they are on HAART. ${ }^{6}$

Villar et al (2007) established a definite short term protective effect of caesarean section on the occurrence of third and fourth degree perineal tears, as well as on postpartum fistulae. ${ }^{24}$.

The benefit of elective caesarean section on fetal outcome in breech presentation at term has been well known since the publication of the 'Term Breech Trial', and has been incorporated as standard practice in many obstetric units. The 'Term Breech Trial' was an international randomized control trial in which patients with a breech presentation at term were randomized to deliver by caesarean section or planned vaginal birth. A substantial reduction of $1.6 \%$ in adverse perinatal outcome was demonstrated in the caesarean section group vs. $5.0 \%$ in the vaginal birth group $(\mathrm{P}<0.01) .39$ 


\section{$\underline{\text { Reasons behind Increasing Caesarean Section Rates }}$}

A variety of complex reasons have been cited to explain the rising trends in caesarean section rates. For example, as progress in the development of surgical and anaesthetic techniques is made, patients and health care provider's perception of the safety of the caesarean procedure has also changed. ${ }^{4}$ Al-Mufti et al (1996) found that $31 \%$ of female obstetricians indicated they would choose a caesarean section in an uncomplicated, singleton pregnancy for themselves. ${ }^{40}$

Different opinions amongst health care providers about what constitutes 'good obstetric care' is bound to have an effect on caesarean section rates. Wu et al (2005) made this evident in a study about the opinions of Maternal-Fetal Medicine specialists and Urogynaecology specialists regarding elective primary caesarean section. They found that $80.4 \%$ of Urogynaecology specialists would perform an elective caesarean section in the absence of medical indication, as compared to the $55.4 \%$ of Maternal-Fetal Medicine specialists $(\mathrm{P}<0.001)$. More than $60 \%$ of the Urogynaecologists cited the role of caesarean section in the prevention of urinary and faecal incontinence, as well as pelvic organ prolapse, as the reasons behind their choice. On the other hand, the Maternal-Fetal Medicine specialists were more concerned about the impact of repeat elective caesarean section on maternal morbidity and mortality. ${ }^{41}$

Social factors also seem to play a role in caesarean section rates. Leone et al (2008) concluded that women from a higher socio-economic background have better access to antenatal services and are at an increased risk of having a caesarean section. They also showed an association between lower caesarean section rates and social exchange of health information between family and friends. ${ }^{42,43}$

Increasing caesarean section rates could also be driven by the expansion of medical indications. This is illustrated by a WHO survey of Caesarean delivery rates in Latin America. In this survey, cephalo-pelvic disproportion (CPD), fetal distress and previous caesarean section have been identified as the top three 
indications for caesarean delivery. ${ }^{4}$ Similarly, the National Sentinel Caesarean Section Audit by the Royal College of Obstetricians and Gynaecologists showed the main indications for caesarean section in England and Wales to be fetal distress (22\%), failure to progress (20\%), previous caesarean section (14\%) and breech presentation $(11 \%){ }^{8}$

Another explanation for the increase in caesarean section rates has been the combination of an increase in primary caesarean section rates and the sharp decline in VBAC. In the US, for instance, the VBAC rate has fallen from $28.3 \%$ in 1996 to $12.7 \% 2002 .^{2}$ Dodd et al (2004) reported similar declines in VBAC rates in Australia and also noted that repeat caesarean section is the most common indication for caesarean delivery in South Australia, comprising $28 \%$ of the overall caesarean delivery rates. ${ }^{44}$ These findings are supported by the RCOG Green-top guideline on Birth After Previous Caesarean Birth, which states that "The proportion of women who decline VBAC, is (in turn), a significant determinant of overall rates of caesarean birth". ${ }^{34}$

Increased malpractice litigation against medical practitioners has been proposed as another important factor behind the increasing rates, especially in private practice. A South African study conducted by Chalmers et al (1992) has shown that $75.3 \%$ of private sector doctors cited "fear of litigation" as one of the reasons for performing caesarean section, compared to $21.2 \%$ of doctors working in state-run hospitals. ${ }^{9}$ Robson reports payments in the United Kingdom for cases of birth related problems that resulted in handicap, of more than 3 million pounds. ${ }^{13}$ Some obstetricians might argue that faced with a situation where there is uncertainty about a successful outcome, performing a caesarean section might be the safest option.

Several studies have shown significantly higher caesarean section rates in the private sector compared to state-run hospitals. Belizán et al (1999) reports private rates to be much higher than public hospitals in Argentina, Chile, Brazil, Mexico, Paraguay and Colombia. Of these countries, three had caesarean section rates exceeding $50 \%{ }^{45}$ A Chilean study by Murray (2000) had similar findings, 
showing private caesarean section rates between 57-83 \%, as compared to 27-28 $\%$ in public hospitals. ${ }^{46}$ South Africa is no different, reporting very high caesarean section rates in the private sector. ${ }^{9,17}$ Another South African study by Lawrie et al (2001) examined caesarean section rates amongst medical doctors. The vast majority (97.8\%) attended antenatal care in private, and it was found that more than $50 \%$ of the primigravid patients expecting a vaginal birth, delivered by caesarean secton. ${ }^{47}$

\section{Caesarean Section on Request}

Caesarean delivery on maternal request (CDMR) is a subset of elective caesarean delivery, defined by the National Institutes of Health as "a caesarean delivery for singleton pregnancy on maternal request, at term, in the absence of any medical or obstetric indications". ${ }^{19}$ Maternal request for caesarean section is increasingly perceived as the reason for the rise in caesarean section rates. The rates for CDMR range from $5 \%{ }^{48}$ to $48 \%{ }^{49}$ for elective caesareans sections. A lack of consensus about what defines maternal request and the inclusion of patients who have certain risks for vaginal delivery in studies about CDMR have lead to a wide range in the rates of caesarean delivery on request. Conclusions drawn from such studies can lead to misleadingly high rates being quoted. For example, Quinlivan et al (1999) reports in a 2-year prospective audit that maternal request was the most frequent indication for elective caesarean section (170 of 633 elective caesareans - $27 \%$ ). Interestingly, the majority of these were patients with a previous caesarean section (16.3\%) and breech presentation $(8.8 \%) .^{50}$ In fact, a very small number of patients had a caesarean section based purely based on personal choice (0.8\%). Similarly, Jackson et al (1998) reports maternal request to comprise $38 \%$ of elective caesarean sections in a yearlong prospective study conducted in the UK. Of these patients, 59.6\% had a previous caesarean section and $22 \%$ had a breech presentation. ${ }^{48}$

In studies that exclude women in labour, and women who had a history of previous caesarean delivery, the rates of CDMR is understandably lower. Gossman et al (2006), for example, collected data from the National Hospital 
Discharge Survey in the US between 1991 and 2004. Women who requested a caesarean section without medical indication comprised $5.03 \%$ of the primary caesarean deliveries. $^{51}$ The National Sentinel Caesarean Section Audit Report reports caesarean section on request to be $7 \% .^{8}$ Since caesarean section on request is not routinely offered in the South African public health care sector, it is unlikely that this factor significantly contributes to the rising caesarean section rate in public sector or 'state' hospitals.

'Fear of childbirth' is often cited as a frequent reason for women requesting caesarean section. ${ }^{52}$ Wiklund et al (2008) investigated fear of childbirth in a group of women requesting caesarean delivery with a group of women planning a vaginal birth. They found that $43.4 \%$ of women requesting caesarean section had a 'clinically significant fear of childbirth' as compared to $6 \%$ in the group planning vaginal delivery. ${ }^{53}$ Rouhe et al (2009) investigated the connection between fear of childbirth and preference for mode of delivery. They found that, although not common, there were higher fear scores in women preferring to have a caesarean delivery. ${ }^{54}$

In a review of 17 articles regarding women's request for caesarean section, McCourt et al (2007) also found that fear of birth, often associated with a previous negative birth experience, as well as a perception of poor care, and concern about the birthing process during a vaginal delivery, as common reasons for requesting caesarean delivery. The other reasons given relate mainly to women's views about safety, and the notion that caesarean section holds fewer risks for the baby and themselves. ${ }^{12}$ In another review, Gamble et al (2007) examined the reasons behind women's request for caesarean section, and deduced that these women were making a decision based on risk assessment. It follows that they are not deciding between two birth options with equal risks, but rather basing their choice on "safety and predictability". 55

In the absence of a randomized control trial comparing the outcomes of CDMR with vaginal birth, there is no consensus about the adverse effects and possible benefits of caesarean section on request. ${ }^{56}$ The ethics about carrying out 
caesarean section on request have been widely debated. The International Federation of Gynecology and Obstetrics (FIGO) stated in 1999 that: "Because hard evidence of net benefit does not exist, performing cesarean sections for nonmedical reasons is ethically not justified". ${ }^{57}$ In stark contrast to this statement, the American College of Obstetricians and Gynecologists released a statement, placing the responsibility of deciding the merits and risks of doing a caesarean section on request on the doctors' shoulders. They stated: "If the physician believes that cesarean delivery promotes the overall health and welfare of the woman and her fetus more than vaginal birth, he or she is ethically justified in performing a cesarean delivery. ${ }^{58}$ The NICE guidelines on caesarean section recommend counselling, with specific attention paid to fear of childbirth and other mental health issues, to women requesting a caesarean section. They also recommend offering a caesarean section if women, after counselling, still insist upon caesarean delivery. ${ }^{6}$

Health care professional's attitudes and willingness to performing CDMR vary. The National Sentinel Caesarean Section Audit Report reports that specialists agreed to at least half of the requests for caesarean section without a medical indication. The threshold for agreeing to these requests differ, for example, consultants would agree to performing CDMR more readily in the scenario of a 42 year old women with no previous pregnancies $(30.9 \%$; $95 \%$ CI - 23.9, 58.6) as compared to the scenario of a 25 year old women with no previous pregnancies $(3.7 \%$; $95 \%$ CI $1.4-7.9) .{ }^{8}$ In a survey about Obstetricians in the United Kingdom and Wales, Cotzias et al (2001) reports that $69 \%$ would agree to perform a caesarean section based on request alone. ${ }^{59}$ Far fewer obstetricians agreed with a woman's right to request a caesarean delivery (only $37.6 \%$ ) in a survey in Denmark about obstetrician's attitude about CDMR. ${ }^{60}$

Maternal choice and satisfaction after birth has become increasingly important in the changing world of obstetrics. This is reflected in the NICE guidelines on caesarean section, which state: "Pregnant women should be offered evidencebased information and support to enable them to make informed decisions about 
childbirth. Addressing women's views and concerns should be recognised as being integral to the decision-making process." 6 In the United Kingdom, two publications, the 'Changing Childbirth' report and the 'Audit Commission Report', emphasized that maternity services needed to become more women-centred and had to encourage women to choose the type of care they preferred. ${ }^{13}$ A law on the rights of pregnant women has been approved in Italy by the Regione Marche, which states: " the active participation of pregnant woman in (decision making during) all the stages of labor and delivery, and in the choice of the route of delivery."61

Various opinions exist about whether women should have the right to choose their mode of delivery. In a study by Chong et al (2003) about women's attitudes in Singapore regarding vaginal and caesarean delivery, 71 \% agreed that women should have the right to request a caesarean delivery. This is a substantial percentage, especially considering that the vast majority (95.1\%) of this group of women, would prefer a vaginal delivery for themselves. ${ }^{62}$ Some studies also show a difference between nulliparous and multiparous women's beliefs regarding the right of choice of mode of delivery. Johanson et al (2000) found that the majority of health care professionals who believed that you should be able to request a caesarean delivery, were nulliparous (52.5\%), as compared to the multiparous group (17\%).63 A Canadian study found similar differences between nulliparous and multiparous women. In this study, $51 \%$ of nulliparous women compared to $28 \%$ of multiparous women stated that women should be offered elective primary caesarean section. ${ }^{64}$

\section{Women's Preference for Mode of Delivery}

There is little consensus about women's preferred mode of delivery. ${ }^{11}$ This is understandable, considering the difference between ethnic groups ${ }^{65}$, parity ${ }^{63,64}$ previous birth experience as well as differences between different countries ${ }^{66}$ and cultures. 
Mazzoni et al (2011) conducted a systematic review and meta-analysis regarding women's preference for caesarean section. This publication contributes to the growing body of evidence that the minority of women actually want do deliver by caesarean section. They reported the general preference for caesarean section to be $15.6 \%$ (95\% CI 12.5 - 18.9). The Americas were found to have the highest preference for caesarean section at $23 \%$ (95\% CI 16.4 - 26.7). Other characteristics associated with high caesarean section preference, were women who had delivered by caesarean section previously (29.4 \%; 95 \% CI 24.4 -34.8), multiparous women (17.5 \%; 95 \% CI 13.4 - 21.8) as well as women in who were interviewed postpartum regarding their anticipated mode of delivery in subsequent pregnancies (22 \%; $95 \%$ CI 15.2 - 29.6).66

As mentioned previously, high caesarean section rates, often of more than $50 \%$, have been reported in the private sector.4,16,17 A Chilean study found that overall, $77.8 \%$ of women preferred vaginal delivery. ${ }^{67}$ Interestingly, even though the caesarean section rates in private were much higher, there was no statistical difference in the preferred mode of delivery between women attending a private and public clinic. Of women attending the public clinic, $11 \%$ preferred a caesarean delivery, compared to the $8 \%$ in women attending the private clinic $(\mathrm{P}=0.74) \cdot{ }^{67}$

There is evidence from studies conducted worldwide, that most women prefer vaginal delivery. In an Australian study, Gamble et al (2001) reported that 93.5 $\%$ of pregnant women between 36 and 40 weeks, preferred vaginal delivery. ${ }^{68}$ Manthata et al (2006) reported similar high preference for vaginal birth (84\%) in a South African study comparing preference for mode of delivery between two different ethnic groups. ${ }^{65}$ Hildingsson et al (2002) reported similar findings in Sweden with only $8.2 \%$ of patients citing caesarean section as their preferred mode of delivery. ${ }^{11}$ Slightly higher preference for caesarean section is reported by Pang et al (2007) in a study conducted among pregnant women in Hong Kong (16.7 \%; $95 \%$ CI 13.8 - 19.6), but the vast majority of patients favoured vaginal 
delivery. ${ }^{69}$ Similar rates for caesarean preference (16.9\%) were found in Italy by Mancuso et al (2006) ${ }^{70}$

In the UK, Kingdon et al (2009) conducted a longitudinal cohort study, comparing preferred mode of delivery at three different points in the pregnancy. They found that most women would want to give birth vaginally and that this preference strengthened over time (68.4\% at booking, compared to $80.7 \%$ in their third trimester). ${ }^{71}$ This was supported by Pang et al (2007), who interviewed women at two points in the pregnancy. They found that the $17.2 \%$ of women wanting a caesarean section early on in pregnancy, decreased to 12.7 $\%$ late in pregnancy. ${ }^{72}$

Gamble et al (2007) concludes in a literature review about caesarean section on request, that despite high caesarean section rates, relatively few women actually prefer caesarean delivery. They also suggest that attributing increasing caesarean section rates to increasing numbers of caesarean section performed on maternal request, might distract from the health professional's impact on the caesarean rates. ${ }^{55}$ This statement is corroborated by a study conducted in a society with high caesarean section rates, where the vast majority of patients' preferred mode of delivery was vaginal birth. Lee et al (2004) reported in a South Korean study, caesarean rates of $37.7 \%$. In their study, $96.4 \%$ of the women interviewed, said that they would prefer vaginal delivery. ${ }^{73}$ It is important to note that the participants in this study were not pregnant, and that recall bias could have influenced the results.

There is limited data on South African women's preference for mode of delivery. This is despite a definite shift in South African obstetric practice towards patients being more centrally involved in decision-making regarding their care, with satisfaction following childbirth becoming increasingly important. The rationale behind this study, therefore, is to gain better insight into women living in Cape Town's preference for mode of delivery. Conducting this study would also give us the opportunity to examine the reasons behind women's preference 
for mode of delivery, and the factors influencing their decision-making, thereby contributing to the broader discourse on this topic. 


\section{AIMS AND OBIECTIVES}

The primary objective:

To determine women's preference for mode of delivery, in a low risk population, during the third trimester of their pregnancy, attending antenatal care at Gugulethu and Mitchell's Plain Midwife obstetric units (MOU's) in Cape Town.

The secondary outcome:

To describe the major reasons for their preferred mode of delivery. 


\section{METHODS}

\section{Study Design}

The study had a cross-sectional descriptive study design of women during their third trimester of pregnancy. These women attended antenatal care at two state-run Midwife Obstetric Units (MOUs) in Gugulethu and Mitchell's Plain.

\section{Study Setting}

In the Western Cape, two thirds of deliveries take place in the Cape Town Metropolitan area. Of these deliveries $48 \%$ take place in MOUs. ${ }^{74}$ There are 11 MOUs providing antenatal care and serving as delivery units for low risk patients in the Metro West maternity service in Cape Town. Midwives and nurses staff the MOUs, and outreach clinics are conducted weekly by doctors from Mowbray Maternity Hospital (MMH). MMH is a secondary level public maternity hospital in the southern suburbs of Cape Town.

During the 2001 Census the population of Mitchell's Plain was estimated to be 305 343, with the majority of this population being Coloured (84.2\%). ${ }^{75}$ Gugulethu was estimated to have a population of 80277 , of which $98.85 \%$ are African. ${ }^{76}$ In an effort to minimize selection bias, participants were recruited at both Mitchell's Plain MOU and Gugulethu MOU, as they represent populations with differing ethnic and cultural demographics. Gugulethu and Mitchell's Plain MOU refer patients with complications in pregnancy to Mowbray Maternity Hospital. Patients from the MOUs with tertiary problems are referred to Groote Schuur Maternity Centre. Groote Schuur Hospital is a tertiary level public hospital, also situated in the southern suburbs of Cape Town.

Caesarean sections are performed in Metro West, as is the case in other public sector maternity facilities in South Africa, for medical indications only. At present there is no protocol in place in these health care facilities regarding caesarean section on request in the absence of medical indications. 


\section{Study Population}

\section{Inclusion Criteria}

- Age: 18 years or more

- Gestational age: 32-40 weeks

- Singleton pregnancy

- Attending antenatal care in a participating MOU

- Planning to deliver at a participating MOU

\section{Exclusion Criteria}

- Contraindication to vaginal delivery

- Medical indication for elective caesarean section

- Malpresentation of fetus

- Previous caesarean section

- Placenta praevia

- Previous classical caesarean section

- Multiple pregnancies

- Severe medical problems (e.g. asthma, epilepsy, cardiac problems)

- Previous neonatal complications (stillborn, early neonatal death)

- Pregnancy following assisted reproductive techniques

\section{Study Methodology}

\section{Questionnaire}

The questionnaire (See appendix A) was adapted from other studies done on women's preference for mode of delivery. ${ }^{77}$ Section A included questions about socio-demographic information namely: age, ethnicity, language, level of education, employment, level of income, housing and sanitation, relationship status and history of substance abuse. Section B related to the obstetric history and divided the participants into primigravid and multigravida women. Questions about HIV status and whether the pregnancy was planned were 
included. In the multiparous group we also collected information about past obstetric history, history of previous instrumental delivery as well as previous NICU admissions. Preferences and perceptions about mode of delivery were explored in Section C. Participants were asked "What do you think is the best way to deliver your baby?" The options were vaginal delivery, caesarean section, or unsure. For the 'vaginal delivery' and 'caesarean section groups', various options were given to explore the reasons why they wanted a specific mode of delivery. Each section had the following responses: 'yes', 'no', or 'unsure' and also included an open ended response. We explored women's knowledge about when they think a caesarean section is necessary. For each of the questions, the possible responses were: 'yes', 'no' or 'unsure' as well as an open-ended response. Finally, we asked participants if they thought women should have the right to request a caesarean section with no medical or obstetric indication.

\section{Recruitment}

The study participants were enrolled during a routine antenatal visit to Gugulethu and Mitchell's Plain MOU during August 2014. Trained interviewers screened the folders of all the women attending the clinic. Women that were eligible for the study were invited to participate and given an information leaflet to keep (see Appendix B). Written consent (see Appendix C) was obtained prior to the interview. The patient information leaflet and consent forms were made available in English, Xhosa and Afrikaans.

It was clearly explained to participants that the questionnaire aimed to record women's opinions and stated preference about mode of delivery, but that the eventual mode of delivery would be determined by current practice in which medical and obstetric factors dictate mode of delivery. The interviewer was not involved in the antenatal care of the participants and the nursing staff at the MOUs was not involved in the interviews. 


\section{Data Collection}

The questionnaire-based interview was conducted in a private room by the trained interviewer in a language that the study participants understood. Each interview lasted approximately twenty minutes. Women's responses were recorded on a hard- copy of the questionnaire by the interviewer. Each study participant was allocated a study number, which appears on the questionnaire form. No personal information was recorded on the questionnaire. This contact data form was stored securely at Groote Schuur Hospital in a locked office, separate from the questionnaire forms to ensure patient confidentiality.

The completed questionnaire forms were collected periodically from the two participating MOU's. The data was entered onto an electronic spread sheet (Microsoft Excel®) which is password protected. Once entered onto the electronic spread sheet, the original questionnaire forms were destroyed.

\section{Sample Size}

The sample size calculation was based on the available literature, indicating different preferences for mode of delivery among primigravidas and multiparous women. The calculation was made with the assumption that $65 \%$ of primigravidas would prefer vaginal delivery, and that $85 \%$ of multigravidas would prefer vaginal delivery. A 2 -sided significance level of $95 \%$ was used and a power of $80 \%$. The ratio of 2:1 multigravidas to primigravidas was used because of the distribution of women attending antenatal clinics at the MOUs. Using these assumptions, the sample required for this study is 55 primigravidas and 110 multigravidas. The total sample size was calculated to be 165 . We planned to recruit 200 women to the study to accommodate possible loss to follow-up, incomplete questionnaires, or women recruited that didn't fit the inclusion criteria. 


\section{Statistical Analysis}

SPSS 22 (data analysis software system) was used to analyse the data with the help of a statistician. A descriptive analysis using frequencies, of women's preferences for mode of delivery was conducted at Gugulethu and Mitchell's Plain MOU's. To evaluate the differences between primigravidas and multigravidas regarding the proportion of women who prefer vaginal delivery, two-way comparisons were tabulated and plotted using bar graphs; this was assessed using the Chi-squared or Fisher's test, depending on which was appropriate. We also looked at women's preference for mode of delivery against other variables such as age, ethnicity, level of education, employment, level of income, relationship status and HIV status. Cross-tabulations were done with either the chi-squared or Fisher's test result, depending on which was more appropriate. The chi-square test was not used if the expected number of observations in each cell of the frequency table was small (below 5). A P-value of $<0.05$ was considered significant. A descriptive analysis was done to describe the major reasons behind women's preference for mode of delivery. We also described women's knowledge about indications for caesarean section as well as their opinion on whether they thought women should be given the choice to request a caesarean section in the absence of a medical or obstetric indication.

\section{Ethical Considerations}

Participation in this study was voluntary and all information was treated confidentially and in accordance with the Helsinki declaration ${ }^{78}$. Informed consent (see Appendix C) was sought from each study participant prior to conducting the interview-based questionnaire. The consent form was made available in English, Afrikaans and Xhosa. A patient information leaflet (see Appendix B) was also given to each study participant providing further information about the study. Permission for this study was obtained from the Department of Obstetrics and Gynaecology Research Committee, the Western 
Cape Health Research Committee and the University of Cape Town Ethics Committee, prior to data collection. (HREC REF: 398/2013) 


\section{$\underline{\text { RESULTS }}$}

We approached 105 women at Mitchell's Plain MOU to participate in the study, 5 of them declined and 2 were excluded based on the study criteria, thus including 98 women. At Gugulethu MOU 107 women were invited to participate in the study, 7 women declined and 3 were excluded, thus 97 women were entered the study. A total of 195 women were included in the study. The recruitment process is depicted in Figure 1.

Figure 1: Flow chart of recruitment process

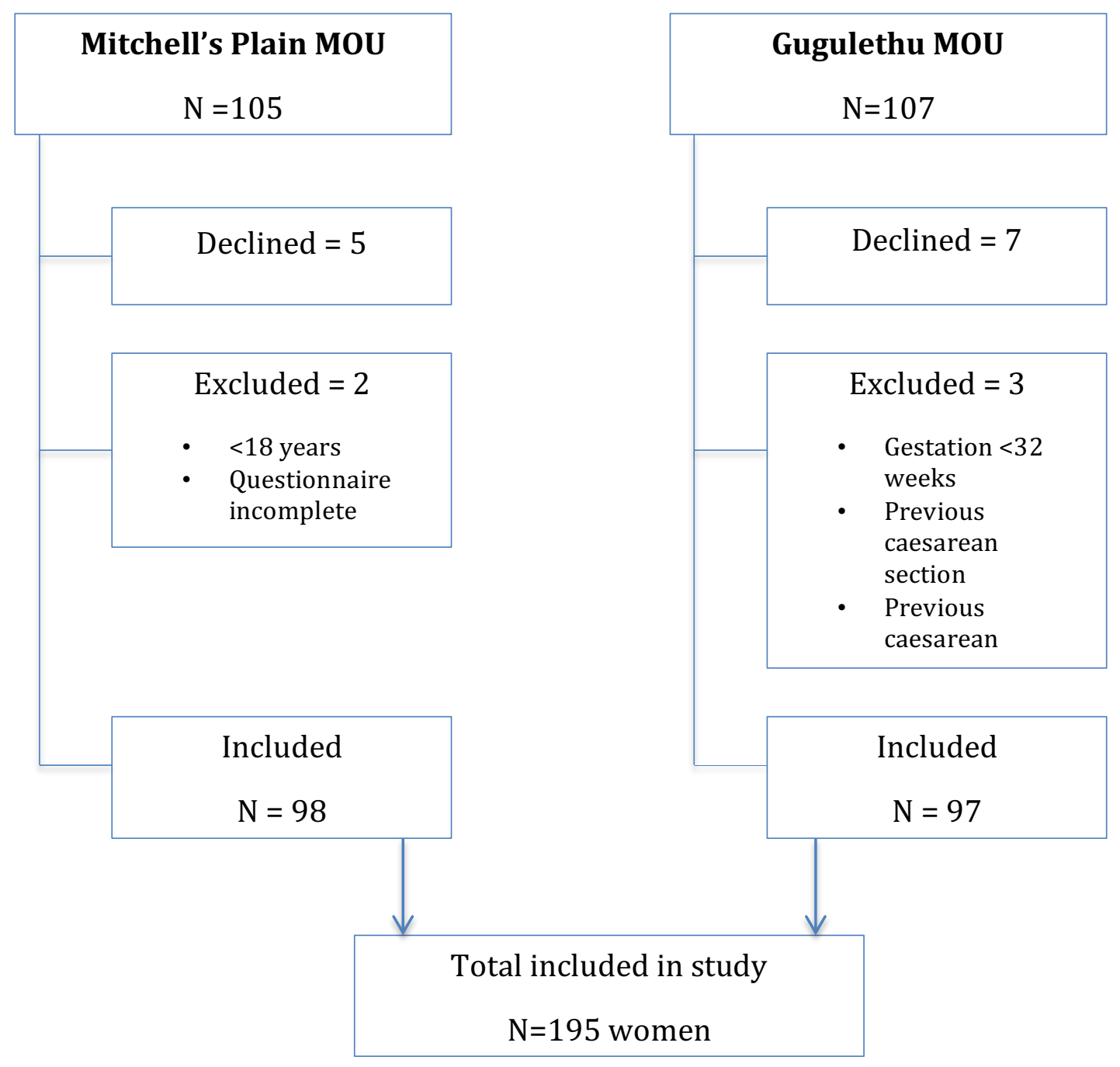


The demographic characteristics of the study population are listed in Table 1. There were 21 women in the teenage group of $18-19$ years $(10.8 \%$ of the total study population), 25 of them were 35 years or older (12.8\%), with 149 women in the 20-34 year age group (74.5\%). Only two ethnic groups participated in the study; 130 women were African (66.7\%) and 65 of the women were coloured (33.3\%). Of the study participants, 116 women were Xhosa speaking (59.5\%), 42 were English speaking (21.5 \%) and 29 were Afrikaans speaking (14.9\%)

Table 1. Demographic Characteristics of Study Participants

\begin{tabular}{|c|c|c|c|}
\hline & $\begin{array}{l}\text { Gugulethu MOU } \\
\qquad \begin{array}{l}\mathrm{N}=97(\%)\end{array}\end{array}$ & $\begin{array}{l}\text { Mitchell's Plain MOU } \\
\qquad \begin{array}{l}\text { N }=98(\%)\end{array}\end{array}$ & $\begin{array}{c}\text { Total } \\
\text { N= } 195(\%)\end{array}$ \\
\hline \multicolumn{4}{|l|}{ Age (years) } \\
\hline $18-19$ & $10(10.3 \%)$ & $11(11.2 \%)$ & $21(10.8 \%)$ \\
\hline $20-34$ & 75 (77.3\%) & $74(75.5 \%)$ & 149 (74.5 \%) \\
\hline 35 or older & $12(12.4 \%)$ & $13(13.3 \%)$ & 25 (12.8\%) \\
\hline \multicolumn{4}{|l|}{ Ethnicity } \\
\hline Black & $96(99.0 \%)$ & $34(34.7 \%)$ & 130 (66.7\%) \\
\hline Coloured & $1(1.0 \%)$ & $64(65.3 \%)$ & 65 (33.3 \%) \\
\hline \multicolumn{4}{|l|}{ Language } \\
\hline Xhosa & $85(87.6 \%)$ & $31(31.6 \%)$ & 116 (59.5 \%) \\
\hline English & $2(2.1 \%)$ & $40(40.8 \%)$ & 42 (21.5 \%) \\
\hline Afrikaans & $2(2.1 \%)$ & $27(27.6 \%)$ & 29 (14.9\%) \\
\hline Shona & $4(4.1 \%)$ & $0(0 \%)$ & $4(2.1 \%)$ \\
\hline Sesotho & $3(3.1 \%)$ & $0(0 \%)$ & $3(1.5 \%)$ \\
\hline Zulu & $1(1.0 \%)$ & $0(0 \%)$ & $1(0.5 \%)$ \\
\hline
\end{tabular}

The socio-economic characteristics of the study population are shown in Table 2. Of the study population, 11 women (5.7 \%) had only primary school education. There were 111 of the participants (56.9\%) who did not complete high school, 
68 completed high school (34.9\%) and 5 women had a tertiary education (2.6 $\%)$. There were 124 (63.3\%) of the women in the study who were unemployed.

Table 2. Socio-Economic Characteristics of Study Population

\begin{tabular}{|c|c|c|c|}
\hline & $\begin{array}{l}\text { Gugulethu MOU } \\
\text { N = } 97(\%)\end{array}$ & $\begin{array}{l}\text { Mitchell's Plain MOU } \\
\text { N = } 98(\%)\end{array}$ & $\begin{array}{c}\text { Total } \\
\text { N = } 195(\%)\end{array}$ \\
\hline \multicolumn{4}{|l|}{ Highest level of education } \\
\hline Primary school incomplete & $5(5.2 \%)$ & $0(0 \%)$ & $5(2.6 \%)$ \\
\hline Primary school complete & $2(2.1 \%)$ & $4(4.1 \%)$ & $6(3.0 \%)$ \\
\hline High school incomplete & $69(71.1 \%)$ & $42(42.9 \%)$ & $111(56.9 \%)$ \\
\hline High school complete & $16(16.4 \%)$ & $52(53.0 \%)$ & $68(34.9 \%)$ \\
\hline Tertiary education & $5(5.2 \%)$ & $0(0 \%)$ & $5(2.6 \%)$ \\
\hline Employed & $29(29.9 \%)$ & $42(42.9 \%)$ & $71(36.4 \%)$ \\
\hline Unemployed & $68(70.1 \%)$ & $56(57.1 \%)$ & $124(63.3 \%)$ \\
\hline \multicolumn{4}{|l|}{ Relationship } \\
\hline Not co-habiting & $52(53.6 \%)$ & $16(16.4 \%)$ & $67(34.4 \%)$ \\
\hline Co-habiting & $15(15.5 \%)$ & $45(45.9 \%)$ & $60(30.8 \%)$ \\
\hline Married & $30(30.9 \%)$ & $36(36.7 \%)$ & $66(33.8 \%)$ \\
\hline Divorced & $0(0 \%)$ & $1(1.0 \%)$ & $1(0.5 \%)$ \\
\hline $\begin{array}{l}\text { Smoking } \\
\text { Yes }\end{array}$ & $2(2.1 \%)$ & $28(28.6 \%)$ & $30(15.4 \%)$ \\
\hline $\begin{array}{l}\text { Alcohol use } \\
\text { Yes }\end{array}$ & $10(10.3 \%)$ & $1(1.0 \%)$ & $11(5.6 \%)$ \\
\hline \multicolumn{4}{|l|}{ HIV status } \\
\hline Positive & $25(25.8 \%)$ & $7(7.1 \%)$ & $32(\mathbf{1 6 . 4 \% )}$ \\
\hline Negative & $72(74.2)$ & $91(92.9 \%)$ & $163(83.6 \%)$ \\
\hline \multicolumn{4}{|l|}{ Planned pregnancy? } \\
\hline Yes & $40(41.2 \%)$ & $62(63.3 \%)$ & $102(52.3 \%)$ \\
\hline No & $57(58.8 \%)$ & $36(36.7 \%)$ & $93(47.7 \%)$ \\
\hline
\end{tabular}


The distribution of relationship status was fairly equal between 67 of the couples not co-habiting (34.4\%), 60 women co-habiting (30.8\%) and 66 married couples (33.8\%). All women that participated in the study knew their HIV status; 163 of them reported that they were HIV negative (83.6\%). Of the participants, 102 women had planned the pregnancy (52.3\%) and 93 of the pregnancies (47.7 \%) were unplanned.

The majority of the participants in our study were multigravidas - 121 of the 195 women (62.1\%). There were 74 primigravidas $(37.9 \%)$ recruited in the study. Of the women in their first pregnancies (primigravidas), 32 (43\%) were from Gugulethu MOU and 42 (57 \%) were from Mitchell's Plain MOU. In the multigravida group, 65 (54\%) were from Gugulethu MOU and 56 (46\%) were from Mitchell's Plain MOU. We compared the distribution of primigravidas and multigravidas using the Pearson chi-square test and although there were a slightly higher percentage of primigravid women interviewed at Mitchell's Plain MOU, we found no significant association between these two groups of women and the two MOU's ( $\mathrm{p}=0.185)$. The distribution of multigravidas and primigravidas recruited in each of the MOU's are shown in Figure 2.

Figure 2. Distribution of Primigravidas and Multigravidas at Gugulethu MOU and Mitchell's Plain MOU

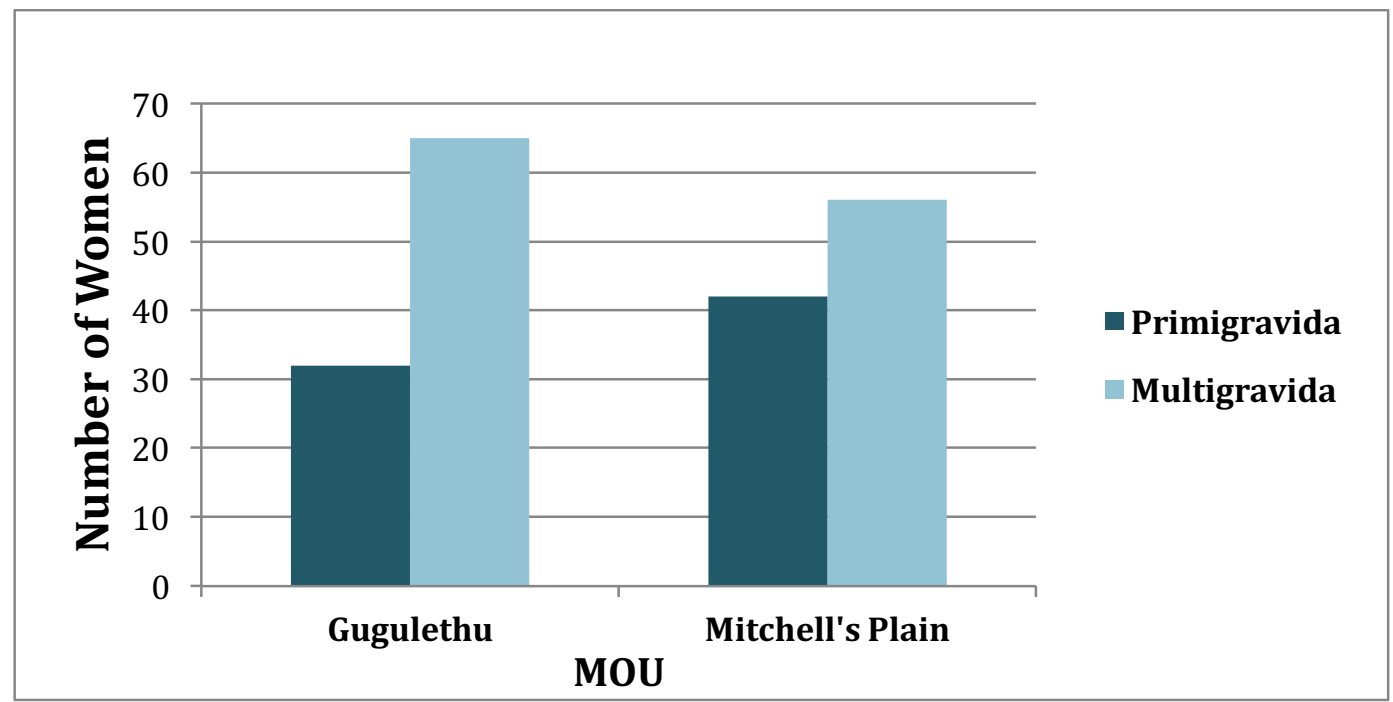


To determine women's preference for mode of delivery, all women were asked: "What do you think is the best way to deliver your baby?" Of the 195 women who participated, 160 (82.1\%) preferred a vaginal delivery, 30 of the women were unsure $(15.4 \%)$ and only 5 of the participants preferred a caesarean section (2.6\%). This is depicted in Figure 3.

\section{Figure 3. Women's Preference for Mode of Delivery}

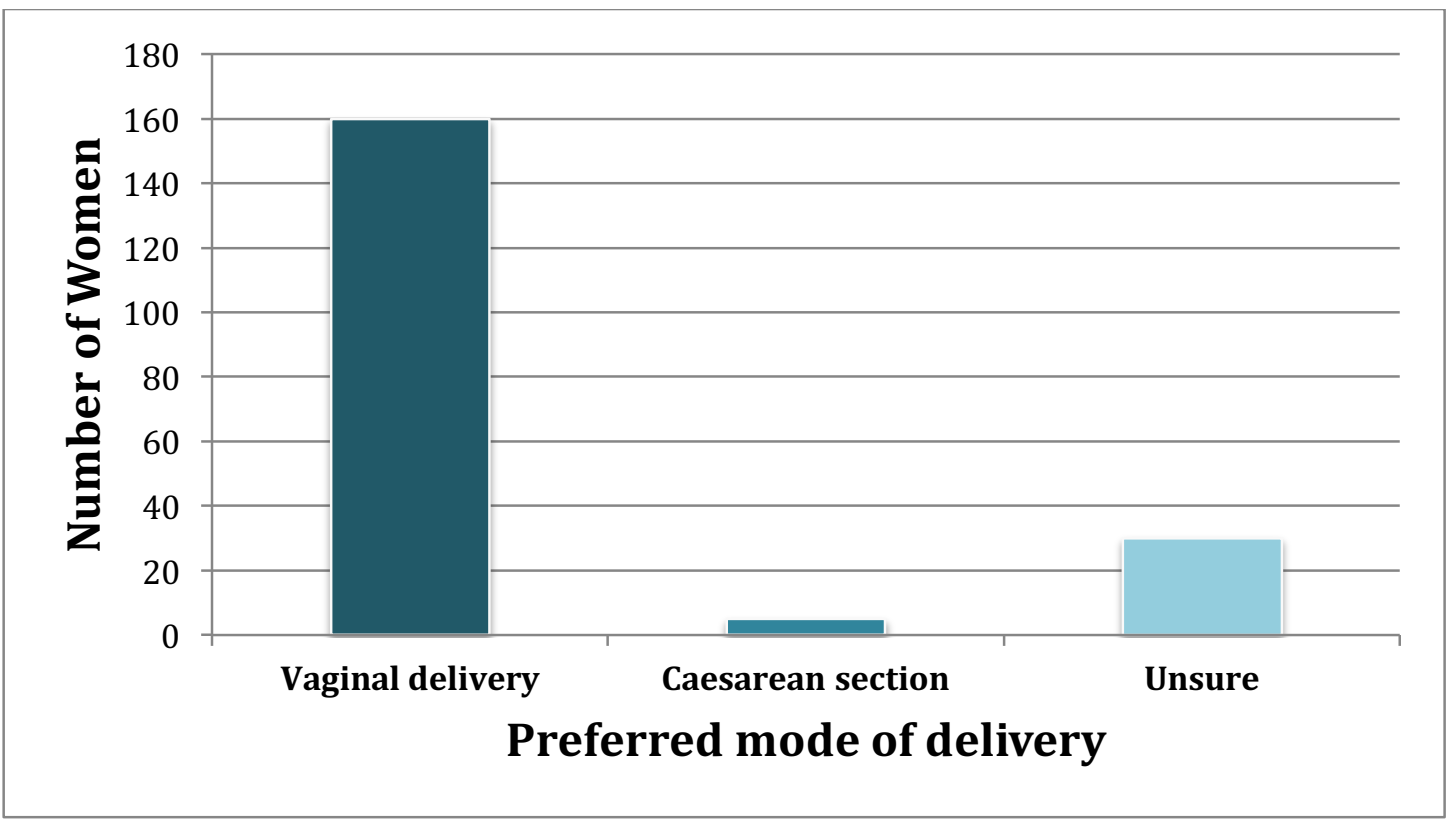

A comparison was made between preference for mode of delivery at Mitchell's Plain MOU and Gugulethu MOU; which is shown in Figure 4. At Mitchell's Plain MOU, 95 of the 98 women (96\%) that were recruited, preferred a vaginal birth as compared to 65 out of 97 women at Gugulethu MOU (67\%). At Mitchell's Plain MOU 2 women ( $2 \%$ of study population) stated a preference for caesarean section and at Gugulethu MOU 3 women (3.1\%) preferred caesarean section. The major difference between the MOU's preferred mode of delivery was found in the 'unsure group'. At Gugulethu there was 29 out of 97 women (29.9\%) who were not sure about their preference, where as Mitchell's Plain MOU only 1 woman (1\%) was not sure about her preference. When comparing the 
preferred mode of delivery between the two MOU's we found a statistically significant association $(\mathrm{p}<0.001)$.

Figure 4. Comparison of Preference for Mode of Delivery Between MOUs

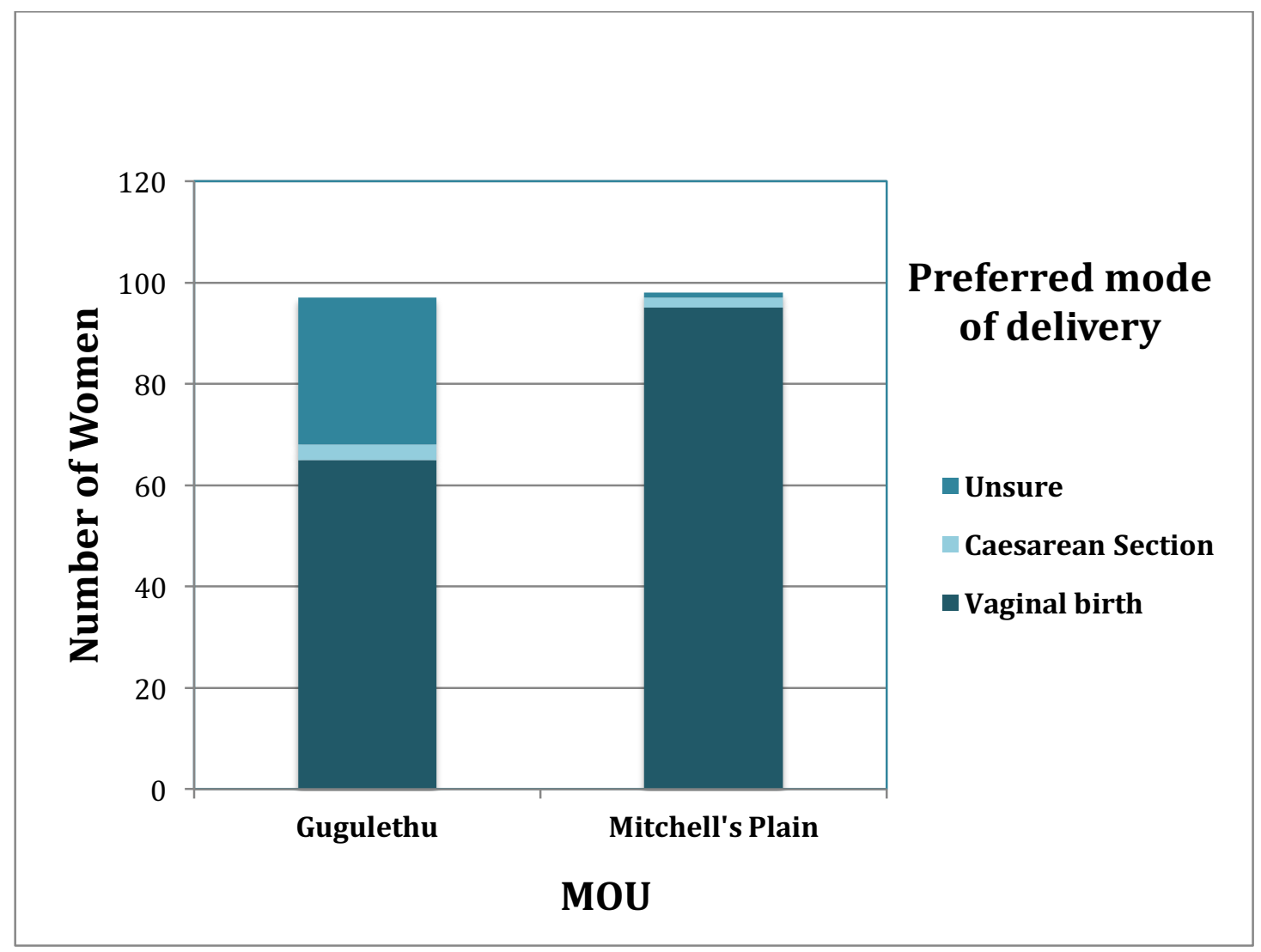

We used the Fishers exact test to compare the preferred mode of delivery between the primigravidas and the multigravidas. Of the primigravidas, 57 (77 \%) preferred vaginal birth, 3 (4.1\%) preferred caesarean section and 14 (18.9 \%) were unsure about their preference. In the multigravida group, 103 (85.1\%) preferred vaginal birth, 2 (1.7\%) preferred caesarean section and 16 (13.2\%) were unsure. This comparison is shown in Figure 5. We found that a slightly higher proportion of multigravida preferred vaginal delivery, however there was no statistically significant association between parity and preferred mode of delivery $(p=0.320)$. 
Figure 5. Comparison of Preference for Mode of Delivery Between

\section{Primigravidas and Multigravidas}

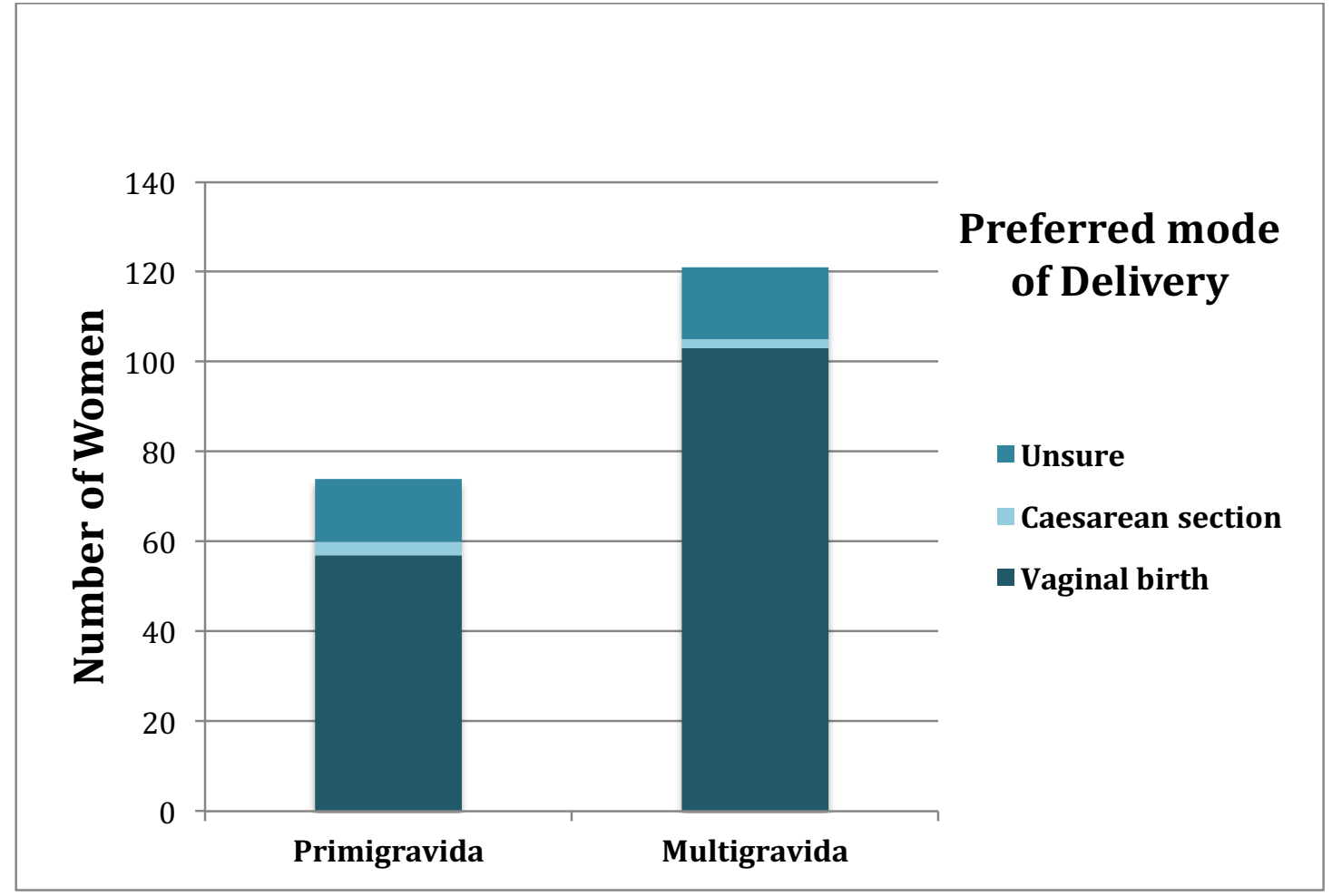

We also compared women's preference for mode of delivery against the other variables, namely: age, ethnicity, level of education, employment, and level of income, relationship status and HIV status.

We compared age and preference for mode of delivery (Figure 6). Of the 21 women in the 18-19 year group, 18 (85.7\%) preferred vaginal birth, 1 (4.8\%) preferred caesarean section and 2 women (9.5\%) were not sure about their preference. In the 20-34 year group 121 of the 149 women (81.2\%) preferred vaginal birth, 2 (1.3\%) preferred caesarean section and 26 (17.5\%) were unsure. In the advanced maternal age group (35 years or older), 21 out of the 25 women (84\%) preferred vaginal birth, 2 (8\%) preferred caesarean section and 2 (8\%) were unsure. Compared to the other age groups, we found that a slightly smaller proportion of women preferred vaginal delivery in the 20-34 year age, and a greater proportion were unsure. We used the chi-squared test to compare 
women's preference for mode of delivery against the age groups and found a statistically significant association between age and preferred mode of delivery $(\mathrm{p}<0.001)$.

Figure 6. Comparison of Preferred Mode of Delivery Between the Different Age Groups

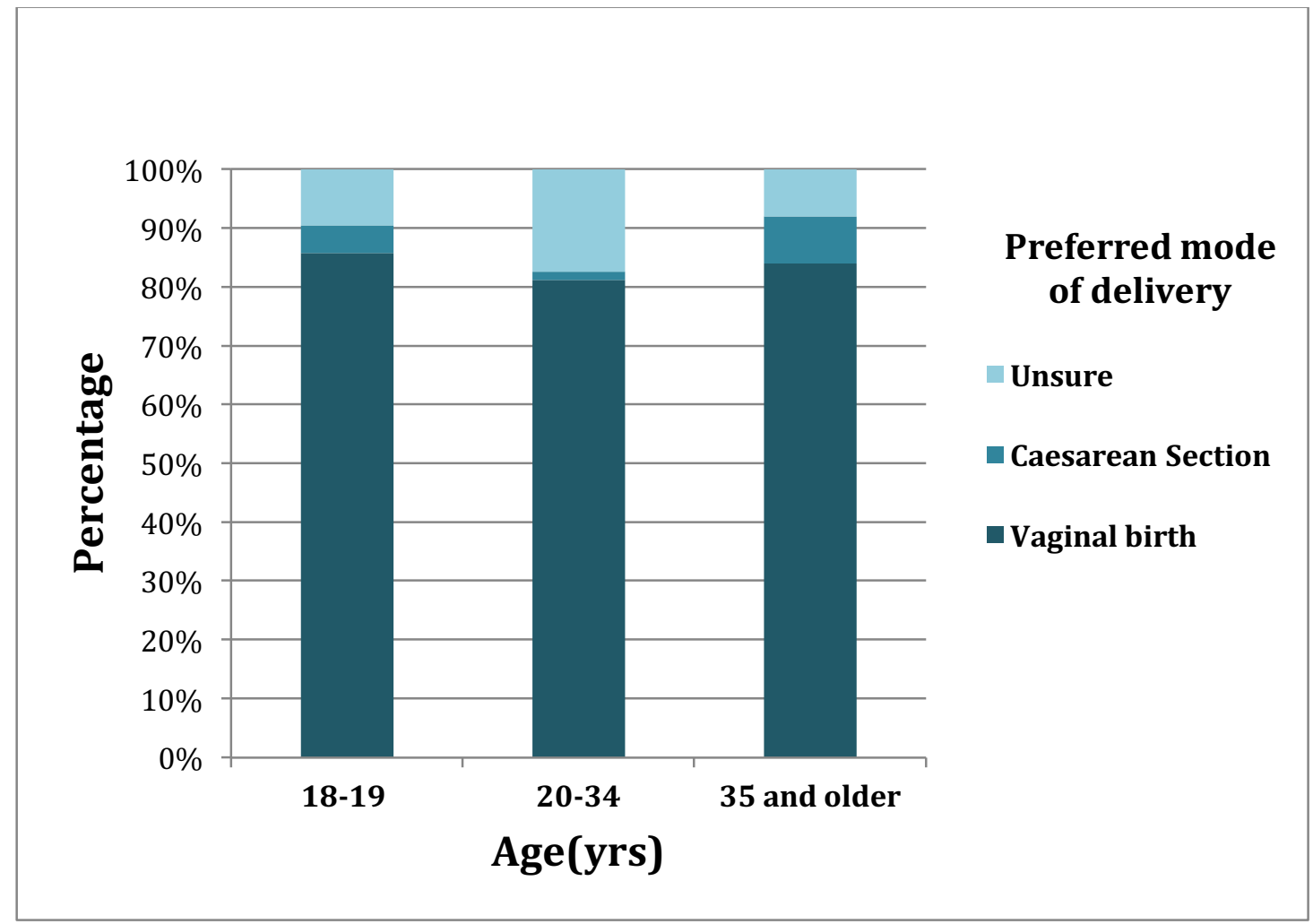

We compared ethnicity and preferred mode of delivery. Of the 130 black women in the study, $98(75,4 \%)$ preferred vaginal birth, 3 (2.3\%) preferred caesarean section and 29 (22.3\%) were unsure. Of the 65 coloured women recruited in the study, 62 (95.4\%) preferred vaginal birth, 2 (3.1\%) preferred caesarean section and 1 woman (1.5\%) was unsure. As depicted in Figure 7, a larger proportion of coloured women preferred vaginal birth (95.4\%) than black women (75.4\%). A larger proportion of black women were unsure about their preference 29 out of $130(22.3 \%)$ compared to the 1 coloured woman (1.5\%). We used the Fisher's exact test to compare Ethnicity and preferred mode of delivery and found a significant association between the two $(\mathrm{p}<0.001)$. 
Figure 7. Comparison of Preferred Mode of Delivery Between the Two Ethnic Groups in The Study

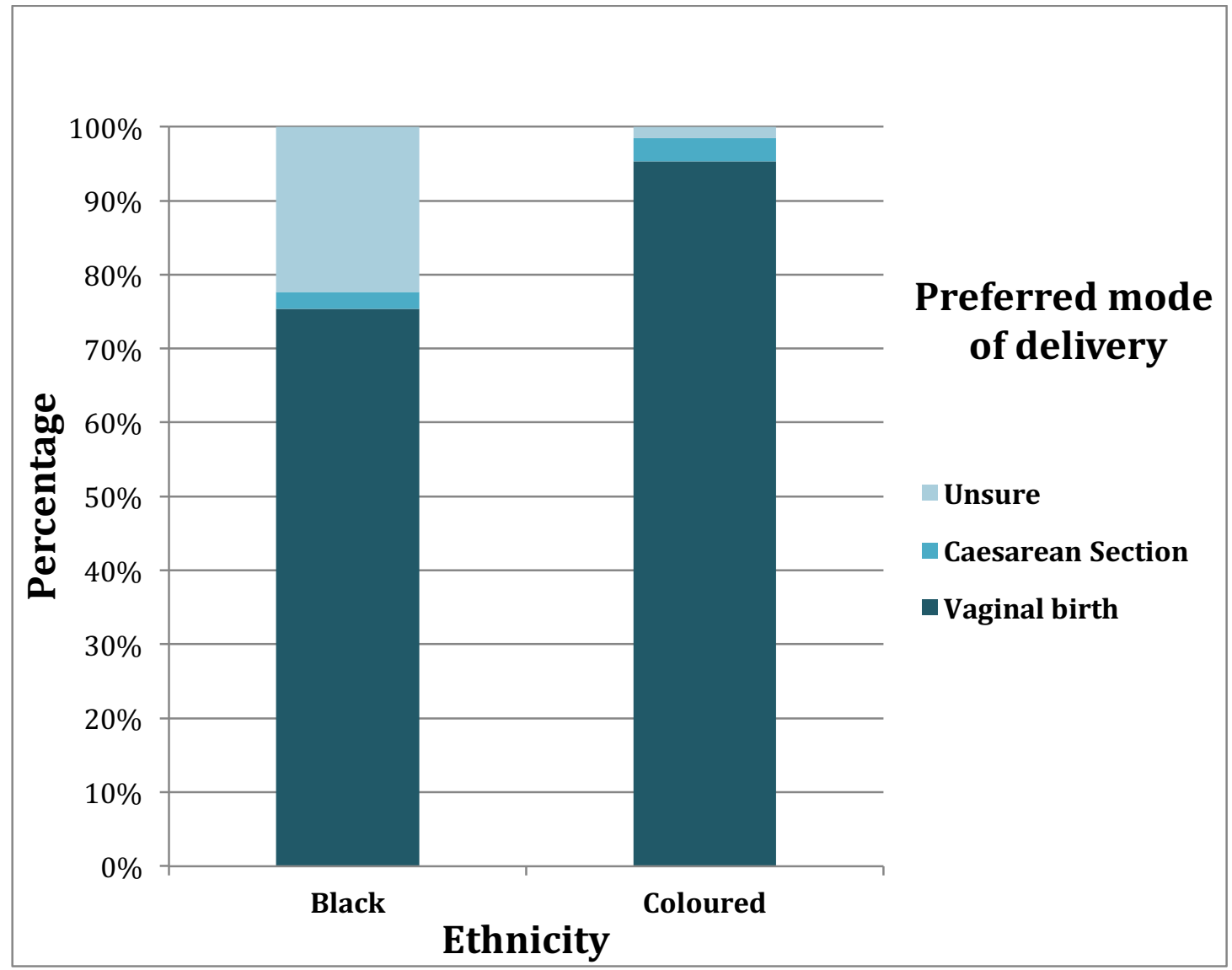

We also compared level of education and preferred mode of delivery. In the group that had not completed primary school, 4 of the 5 women (80\%) preferred vaginal birth, none preferred a caesarean section and 1 (20\%) was unsure. Of the 6 women in the group that had completed primary school, 5 (83.3 $\%)$ preferred vaginal birth, none preferred a caesarean section and 1 woman $(16.7 \%)$ was not sure of her preference. In the group who had not completed high school, 87 of the 111 (78.4\%) preferred vaginal birth and 4 (3.6\%) preferred caesarean section, whilst $20(18 \%)$ were unsure. In the group who had completed high school, 62 of the 68 (91.2\%) stated a preference for vaginal delivery, 1 (1.5\%) woman preferred delivery by caesarean section and 5 (7.4 \%) 
were unsure of their preference. In the small group that had a tertiary education, 2 of the 5 women (40\%) preferred vaginal delivery, none preferred caesarean section and 3 of the 5 women (60\%) were unsure. We used the Fisher's Exact Test to compare level of education and mode of delivery and found no significant association $(p=0.81)$ as depicted in Figure 8 .

Figure 8. Comparison of Preferred Mode of Delivery and Different Education Levels

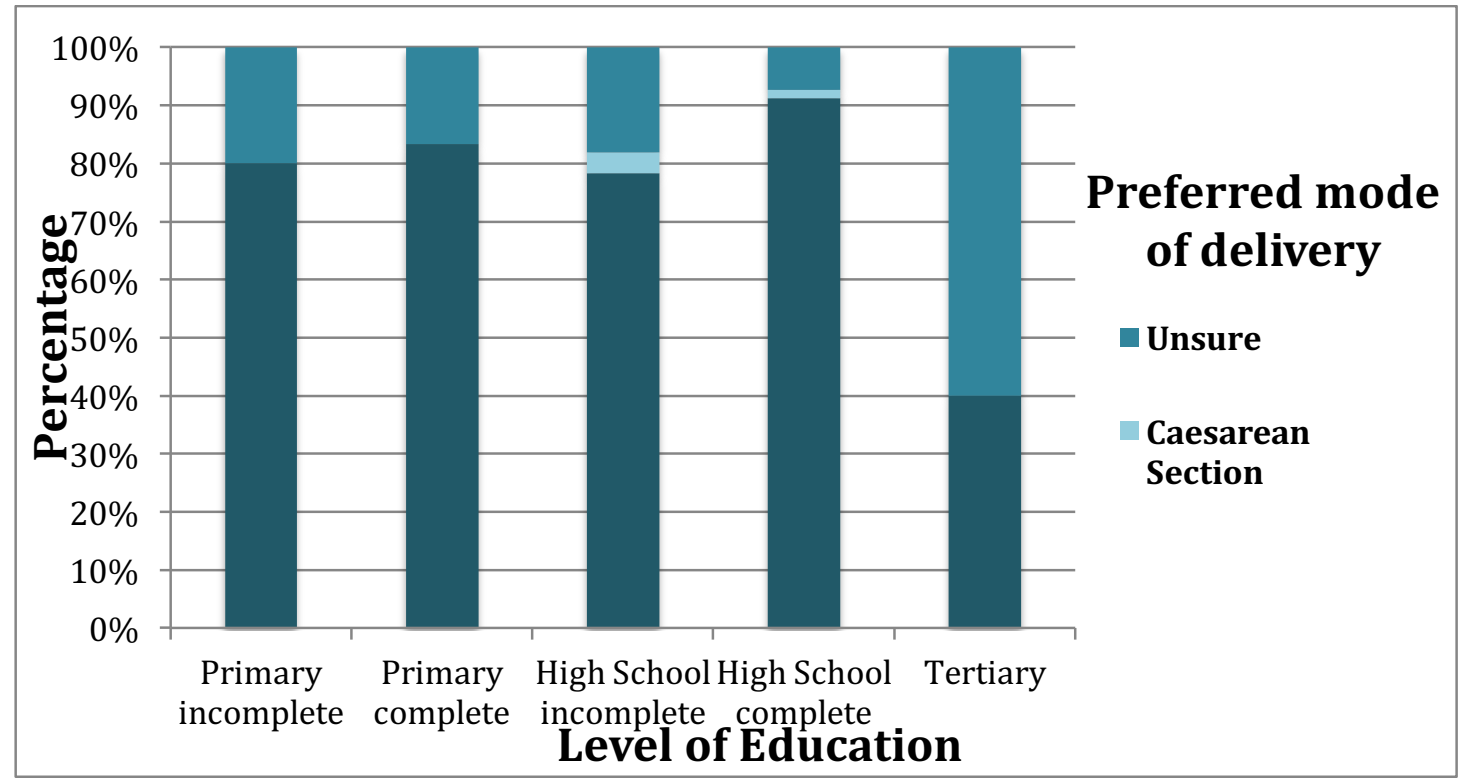

We compared the preference for mode of delivery and employment and found that of the 71 women who were employed, 59 (83.1\%) preferred vaginal birth, 1 woman (1.4\%) preferred caesarean delivery and 11 (15.5\%) were unsure. In the group who was unemployed, 101 of 124 women (81.4\%) preferred vaginal birth, 4 (3.3\%) caesarean delivery and 19 (15.3\%) were unsure of their preference. Only two women who participated in the study were health care professionals, and both of them preferred vaginal delivery. No significant association could be demonstrated between the group of women who were 
employed or not and their preferred mode of delivery, using the Fisher's Exact Test $(p=0.840)$.

In the low-level income group (< R3000), 32 (78\%) of women preferred vaginal birth, 1 woman preferred (2.4\%) caesarean section delivery and 8 (19.5\%) were unsure. The mid-level income group (R3000 - R10 000), 26 (92.9 \%) reported a preference for vaginal birth, $2(7.1 \%)$ were unsure. None of the women in this group preferred a caesarean section. There were only 2 women in the high-level income group (> R10 000), one woman preferred vaginal birth and the other woman were unsure of her preference. We found a tendency for fewer middle-income women to be unsure of their preferred mode of delivery and preferring vaginal delivery. We used the Fisher's exact test to evaluate the difference between the different income groups and preference for mode of delivery, and found no significant association between the two $(p=0.420)$.

Comparing relationship status with preferred mode of delivery, we found that in the group who had a boyfriend but was not co-habiting, 50 (74.6\%) wanted a vaginal birth, 1 (1.5\%) a caesarean section and 16 (23.9\%) were unsure. In the co-habiting group, 54 (90\%) preferred a vaginal birth, 2 (3.3\%) a caesarean section and 4 (6.7 \%) were unsure. The married group reported vaginal birth preference for 54 of the 66 women (81.8\%), caesarean section preference for 2 (3.0\%) and 10 of them (15.2\%) were unsure. Lastly, there was only 1 woman (100\%) in the divorced group, and she preferred a vaginal birth. We used the Fisher's exact test to evaluate relationship status and preferred mode of delivery and found no significant association between the groups ( $p=0.137)$.

We compared HIV status and preferred mode of delivery and found that a large group of women who were HIV negative, preferred vaginal delivery. This is depicted in Figure 9. Of the 163 women who were HIV negative, 141 (86.5\%) preferred vaginal birth, 4 (2.5\%) preferred caesarean section and 18 (11.0\%) were unsure. In the HIV positive group 19 of the 32 women (59.4\%) preferred vaginal birth, 1 woman (3.1\%) preferred caesarean delivery and 12 (37.5\%) 
were unsure of their preference. We found a significant association between HIV status and preferred mode of delivery using the Fisher's exact test $(\mathrm{p}<0.001)$.

\section{Figure 9. Comparison of Preferred Mode of Delivery and HIV Status}

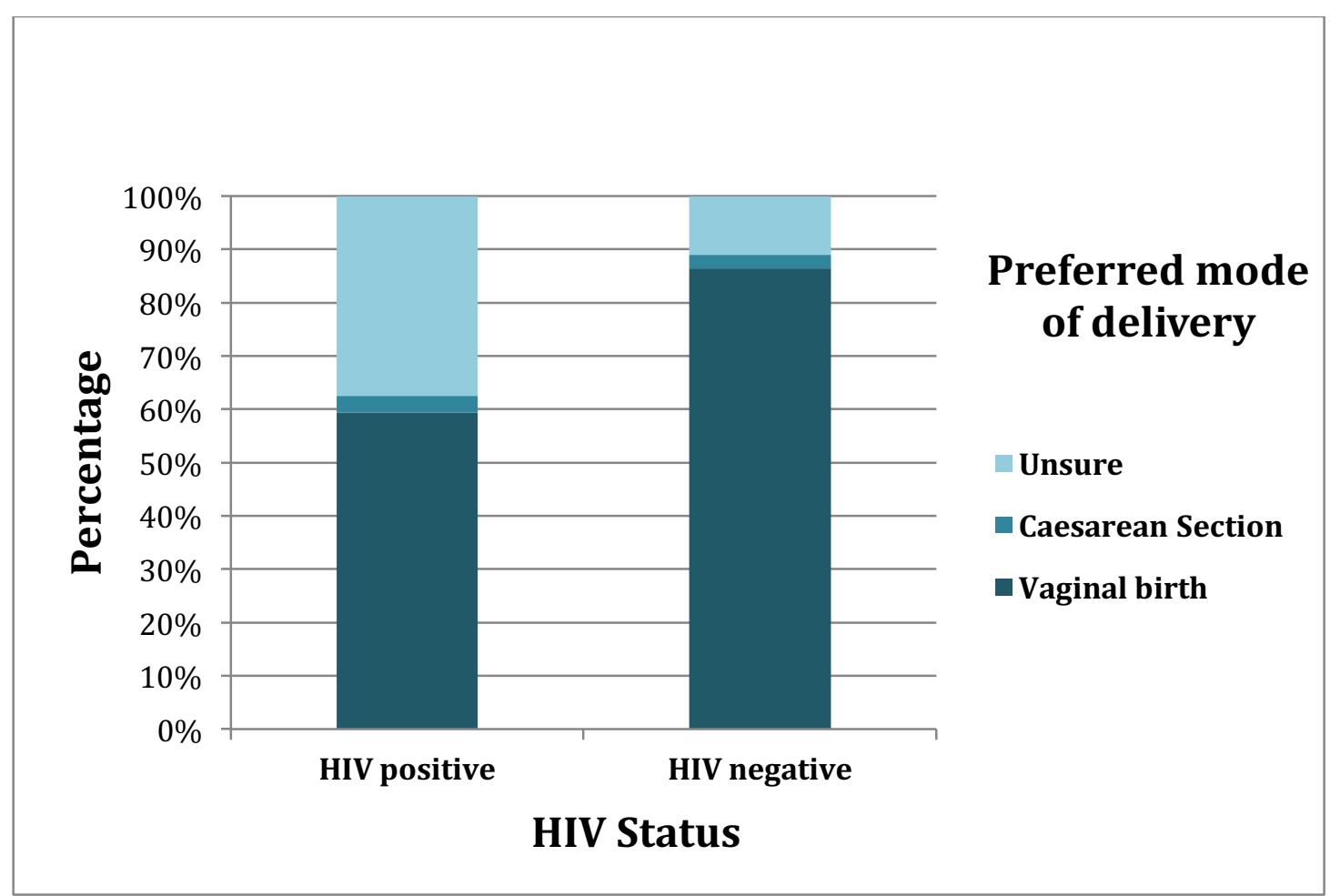

As this study was conducted in a low risk population group, only 7 out of the 121 multigravidas had a previous instrumental delivery (5.8 \%) and 6 of them (85.7 \%) preferred a vaginal birth and only one woman (14.3\%) preferred a caesarean section. Only two women had babies who were admitted to NICU previously $(1.65 \%)$. One of them preferred a vaginal birth and the other preferred a caesarean section.

The majority of women (160 out of 195 women) preferred to deliver vaginally. The reasons given by these women are listed in Table 3. The most common reason was their wish to be home sooner, cited by 154 of 160 women (96.2\%) who preferred vaginal birth. The belief that they will be able to care for their baby better when having a vaginal birth, was cited by 153 women (95.6\%). Another frequent reason given by 153 women (95.6 \%) in this group. was the perception that vaginal birth is safer for the baby and 150 women (93.7\%) stated 
that vaginal birth is also safer for them. Other reasons listed were the desire to have a 'natural' birth experience: 149 women (93.1\%), and the belief that they will be able to breastfeed their baby sooner 147 women (91.9\%). Of the women preferring a vaginal birth, 144 (90\%) agreed that they were afraid of an operation and thought vaginal birth is less painful than an operation. The least frequent reason for preferring a vaginal birth was the statement 'I don't want a scar', cited by 127 women (65.1\%). None of the participants gave a response to the open ended questions.

Table 3. Reasons Behind Women's Preference for Vaginal Delivery

\begin{tabular}{lccc}
\hline $\begin{array}{l}\text { Women's reasons for } \\
\text { preferring vaginal birth }\end{array}$ & Yes & No & Unsure \\
& $\mathbf{N}(\%)$ & N (\%) & N (\%) \\
\hline I will be home sooner & $154(96.2)$ & $5(3.1)$ & $1(0.6)$ \\
\hline I can care for my baby better & $153(95.6)$ & $5(3.1)$ & $2(1.3)$ \\
$\begin{array}{l}\text { Vaginal birth is safer for my } \\
\text { baby }\end{array}$ & $153(95.6)$ & $2(1.3)$ & $5(3.1)$ \\
\hline $\begin{array}{l}\text { Vaginal birth is safer for me } \\
\text { I want a 'natural' birth }\end{array}$ & $150(93.7)$ & $2(1.3)$ & $8(5.0)$ \\
\hline $\begin{array}{l}\text { I can breastfeed sooner } \\
\text { I am afraid to have an } \\
\text { operation }\end{array}$ & $149(92.1)$ & $6(3.8)$ & $5(3.1)$ \\
\hline $\begin{array}{l}\text { Less painful than an } \\
\text { operation }\end{array}$ & $144(90.0)$ & $12(7.5)$ & $4(2.5)$ \\
\hline \begin{tabular}{l} 
I don't want a scar \\
\hline
\end{tabular} & $144(90.0)$ & $7(4.4)$ & $9(5.6)$ \\
\hline
\end{tabular}

The reasons given by women preferring a caesarean section (5 out of 195 women) are listed in Table 4. All five women (100\%) cited 'fear of vaginal birth' as a reason for preferring a caesarean section. Four of the five women (80\%) 
worried about losing bladder or bowel control. The belief that caesarean section is safer for themselves and the baby, less painful than vaginal birth, the ability to plan the birth, not wanting vaginal cuts or tears and a concern about vaginal prolapse was listed by 3 of the 5 women (60\%). The least popular reasons given, were cited by 2 women (40\%) also wanting sterilization as well as the perception of better sexual function in future with caesarean section.

Table 4. Reasons for Preferring Caesarean Section

\begin{tabular}{|c|c|c|c|}
\hline $\begin{array}{l}\text { Women's reasons for } \\
\text { preferring caesarean section }\end{array}$ & $\begin{array}{c}\text { Yes } \\
\text { N (\%) }\end{array}$ & $\begin{array}{c}\text { No } \\
\text { N (\%) }\end{array}$ & $\begin{array}{c}\text { Unsure } \\
\text { N (\%) }\end{array}$ \\
\hline $\begin{array}{l}\text { I am afraid to give birth } \\
\text { vaginally }\end{array}$ & $5(100)$ & 0 & 0 \\
\hline $\begin{array}{l}\text { I worry about losing bladder } \\
\text { and bowel control }\end{array}$ & $4(80)$ & $1(20)$ & 0 \\
\hline $\begin{array}{l}\text { Caesarean section is safer for } \\
\text { me }\end{array}$ & $3(60)$ & 0 & $2(40)$ \\
\hline $\begin{array}{l}\text { Caesarean section is safer for } \\
\text { my baby }\end{array}$ & $3(60)$ & 0 & $2(40)$ \\
\hline $\begin{array}{l}\text { It is less painful than vaginal } \\
\text { delivery }\end{array}$ & $3(60)$ & 0 & $2(40)$ \\
\hline I can plan the birth & $3(60)$ & $1(20)$ & $1(20)$ \\
\hline $\begin{array}{l}\text { I don't want vaginal tears and } \\
\text { cuts }\end{array}$ & $3(60)$ & $1(20)$ & $1(20)$ \\
\hline Worry about vaginal prolapse & $3(60)$ & $2(40)$ & 0 \\
\hline Requesting a sterilization & $2(40)$ & $3(60)$ & 0 \\
\hline $\begin{array}{l}\text { Better sexual function in } \\
\text { future }\end{array}$ & $2(40)$ & $2(40)$ & $1(20)$ \\
\hline
\end{tabular}

The participant's knowledge and beliefs about indications for caesarean section are listed in Table 5. The most frequent indication to which 171 (87.7\%) of women agreed necessitates a caesarean section were breech presentation. Of the study participants, 167 (87.7 \%) cited 'small hip bones' as an indication for 
caesarean section delivery. The third most popular reason reported by 157 women (80. 5 \%), is 'if the baby is very big'. Being HIV positive was the indication cited by 169 (86.7 \%) women as the least popular indication for caesarean section delivery. Another infrequent indication was: a previous caesarean section, with 157 women (80.5\%) not agreeing that this necessitates a caesarean section.

Table 5. Women's Knowledge About Caesarean Section Indications

\begin{tabular}{|c|c|c|c|}
\hline Indication for Caesarean Section & Yes & No & Unsure \\
\hline & N (\%) & N (\%) & N (\%) \\
\hline Breech presentation & $171(87.7)$ & $4(2.0)$ & $20(10.3)$ \\
\hline When your hip bones are too small & $167(85.6)$ & $12(6.2)$ & $16(8.2)$ \\
\hline If the baby is very big & $157(80.5)$ & $20(10.3)$ & $18(9.2)$ \\
\hline $\begin{array}{l}\text { When the baby is not yet born } \\
\text { after your due date }\end{array}$ & $79(40.5)$ & $105(53.9)$ & $11(5.6)$ \\
\hline $\begin{array}{l}\text { When you ask for a caesarean } \\
\text { section }\end{array}$ & $78(40)$ & $112(57.4)$ & $5(2.6)$ \\
\hline If you have a twin pregnancy & $49(25.1)$ & $85(43.6)$ & $61(31.3)$ \\
\hline $\begin{array}{l}\text { If you've had a caesarean section } \\
\text { before }\end{array}$ & $19(9.7)$ & $157(80.6)$ & 19 (9.7) \\
\hline When you are HIV positive & $13(6.7)$ & $169(86.6)$ & $13(6.7)$ \\
\hline
\end{tabular}

All women were asked whether they believed women should have the right to request a caesarean section. The responses are depicted in Figure 10. Just over half of women that participated in the study, 106 out of 195 (54.4\%) did not believe women should be given this right, 14 women were unsure (7.2\%) and 75 
women (38.5\%) believed that women should have the right to request a caesarean section in the absence of a medical or obstetric indication.

Figure 10. Women's Right to Request a Caesarean Section

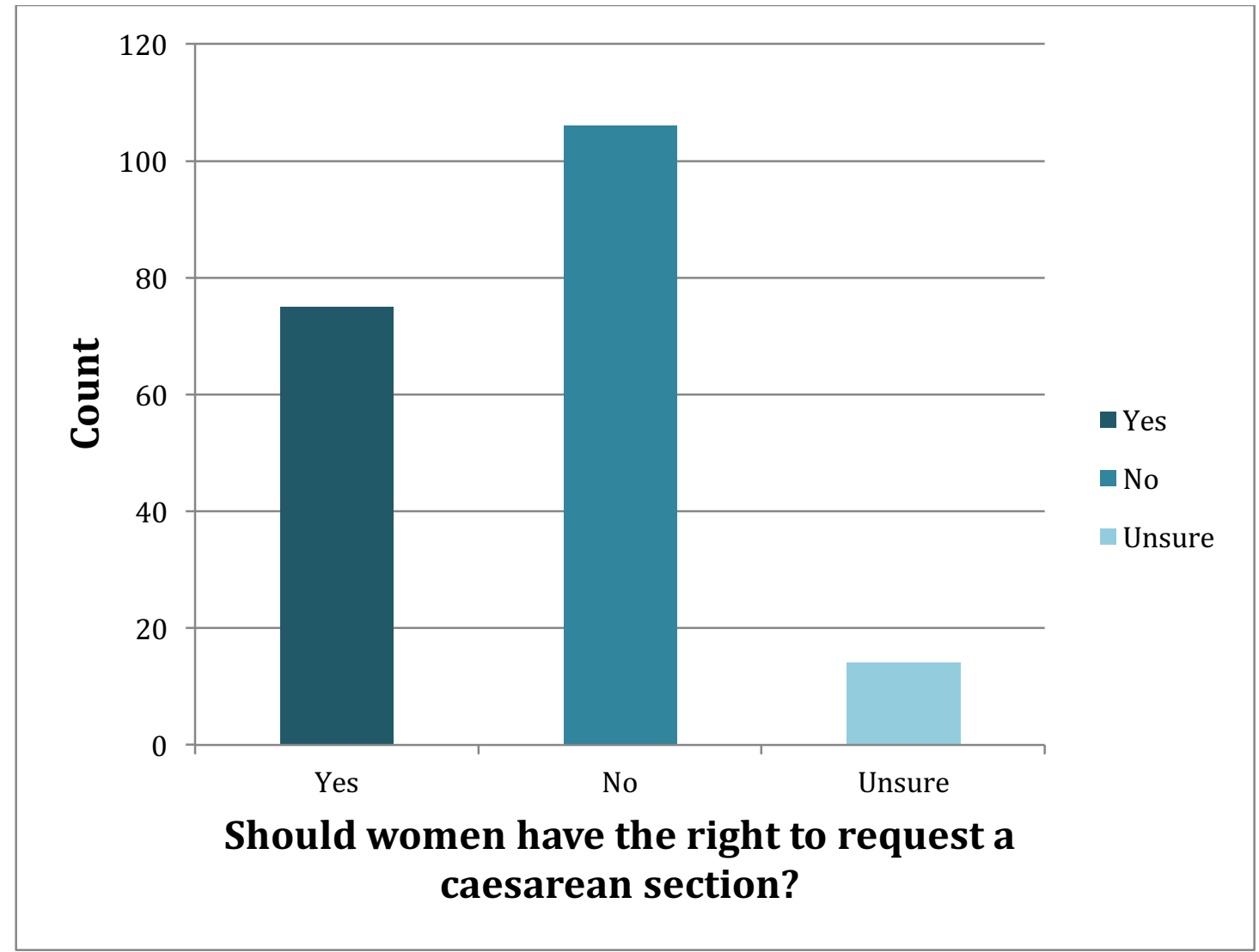




\section{DISCUSSION}

Women's preference for mode of delivery is a topic that has been researched and debated extensively in many parts of the world. Women's autonomy, birth satisfaction and active involvement in the decision-making process regarding the method and way they want to deliver their babies, have become increasingly important. Key publications, such as the NICE guidelines on caesarean section', the 'Changing Childbirth Report,' and the 'Audit Commission Report'13 brought about a change in how health care practitioners and women see their roles in the birthing process. The focus is increasingly placed on a more women-centred approach, with choice for mode of delivery being encouraged in some maternity centres.

In the South African setting, very little is known about women's preference for mode of delivery. Caesarean section on request is not routinely offered in the public sector, and most obstetric units do not have a formal policy regarding this. Although caesarean section rates in South Africa have also been rising in the state and private sectors ${ }^{16,17}$, the impact of maternal request on these rates is unknown.

\section{Preference for mode of delivery}

Of the 195 women who participated in our study, 160 (82.1\%) indicated a preference for vaginal delivery. A few explanations for this preference might be postulated. Our study population was low risk, and by attending antenatal care at the MOU, the participants in our study probably anticipated a vaginal birth. Caesarean section is also not routinely offered in state run facilities, and hence might not even be considered as an option for most of women in our study. From our literature review, it is also evident, that women are often influenced in their preferred mode of delivery by opinions and experiences of family members and friends. Vaginal birth might be considered the norm and is probably 
universally accepted by the members of these communities. Only 5 (2.6\%) of the study participants preferred a caesarean delivery.

Most women in our study were from a low socio-economic background with a minority of women having completed high school (34.9\%) Most of the women in our study were unemployed (63.3\%). This means that most of these women will probably not have easy access to the internet, magazines and newspapers and as a whole, might not have a good baseline knowledge of the risks and benefits of caesarean section, therefore being reluctant to accept this as a preferred mode of delivery. A substantial part of the study population was unsure about their preferred mode of delivery (15.4\%). This probably reflects a lack of discussion by health care providers with pregnant women during the antenatal period about mode of delivery.

Our study was conducted in a low risk population. We wanted to eliminate the risk of bias from high risk patients, who might be more inclined towards choosing a caesarean section because of pre-existing medical or surgical problems. We recruited women from two MOUs with different demographics regarding ethnicity and parity. The majority of women were between 20-34 years old (74.5\%), African (66.7\%), and Xhosa speaking (59.5\%). More than half of the participants indicated that their pregnancy was planned (52.3\%).

There is an increasing body of evidence supporting our hypothesis that the majority of women prefer vaginal delivery to caesarean section. Our findings of high preference for vaginal delivery is in keeping with another South African study by Manthata et al (2005) reporting vaginal birth preference of $84 \% .65$ Some studies showed an even higher preference for vaginal delivery than ours. An Australian study by Gable et al (2001) reported a preference for vaginal delivery of $93.5 \%{ }^{68}$ Chong et al (2003) indicated that $95.1 \%$ of women in their study conducted in Singapore, preferred vaginal delivery. ${ }^{62}$

In contrast with our findings, there are some studies that reported a higher preference for caesarean section than the $2.6 \%$ reported in our study 
participants. In a Swedish study, Hildingsson et al (2002) reported $8.2 \%$ of women preferred a caesarean delivery. ${ }^{11}$ Mancuso et al (2006) indicated in their study about Southern Italian women's preference for mode of delivery, that 16.9 $\%$ preferred caesarean delivery. ${ }^{70}$ Similar to our study, their population group was also low risk, and they also excluded women who had a previous caesarean section. A meta-analysis by Mazzoni et al (2010) also reported higher caesarean section preference than our study (15.6\%; CI 12.5 - 18.9). ${ }^{66}$ It is important to note, however, that women who had a previous caesarean section were included in this meta-analysis, unlike our study. This group of women had a higher preference for caesarean section (29.4\%; CI 24.4 - 34.8), compared to the group who didn't have a previous caesarean section (10.1\%; CI 7.5-13.1).66

The characteristics of the women who preferred a caesarean section, could not be properly compared to the vaginal birth preference group, due to the small number of women in this group (5 out of 195). Of the women preferring caesarean delivery, three were African and Xhosa speaking and two were Coloured and English speaking. Most of the women who did not complete high school, were unemployed, and HIV negative (4 out of 5). Three were primigravidas and two were multigravidas. One of the multigravidas had a previous instrumental delivery and a baby that was admitted to NICU. The other multigravida had a previous uncomplicated live birth.

When comparing the distribution of preference for mode of delivery between the two MOUs, $96 \%$ of women at Mitchell's Plain MOU preferred a vaginal birth as compared to the $67 \%$ of women at Gugulethu MOU who preferred a vaginal birth. This difference can be explained by the larger portion of women in the 'unsure' group, attending antenatal care at Gugulethu (96.7\%), compared to Mitchell's Plain (3.3\%). Most of the studies looking at women's preference for mode of delivery did not include an option of 'uncertain' or 'undecided' in their possible responses. The group of unsure women in our study, however, is much larger than the $2.3 \%$ of unsure women in the South African study by Manthata et al (2005).65 Most of the group of women who were unsure about their 
preference for mode of delivery, were between 20-34 years of age (86.7\%) and African (96.7\%). The majority of these women did not complete high school (66.7\%), were unemployed (63.3\%), not co-habiting with their partners (53.3 $\%)$ and HIV negative (60\%). Lack of access to information and education about both methods of delivery might be the reason behind such a significant number of women being unsure about their preference. This could also be related to the fact that Gugulethu MOU had a higher proportion of black ethnicity and a higher proportion of HIV positive women, all found to be separately associated with preference for mode of delivery. We found a significant association between MOU and preferred mode of delivery $(\mathrm{p}<0.001)$.

Of the 149 women in the 20 - 34 year age group, 121 (81.2\%) preferred vaginal birth. This is a large group of women, but proportionally smaller, when compared to the 18 of 21 women (85.7\%) in the 18-19 year age group and 21 of the $25(84.0 \%)$ of the women in the group $\geq 35$ years who preferred vaginal birth. We found a statistically significantly association between age and preference for mode of delivery $(\mathrm{p}<0.001)$. This association could possibly be explained by the fact that most of the women in our study population were in the 20 - 34 year age group. Of the 71 women in our study who were employed, 56 of them (78.9\%) were in the age group of 20 - 34 years. These women possibly prefer a vaginal birth, because they can return to work sooner and contribute to their family income. Being home sooner was also the most common reason cited by women as the reason for why they preferred a vaginal birth. In contrast to our study, Gamble et al (2001) found no association between mode of delivery preference and age or ethnicity. Similar to our study, however, they found no association between marital status, level of education or occupation. ${ }^{68}$

In the group of Coloured women, 62 of 65 (95.3\%) preferred vaginal birth compared to 98 of 130 African women (75.4\%). The discrepancy in the preference for vaginal birth between these two ethnic group, with a larger group of Coloured women preferring vaginal birth, could be due to the 'unsure' group of which 29 of the 30 (96. 7 \%) were African women. We found a statistically 
significant association between mode of delivery and ethnicity $(\mathrm{p}<0.001)$. Our study findings are in contrast to another South African study by Manthata et al (2006) who found no difference in preferred mode of delivery between two ethnic groups. 65

In the group of women who were HIV negative, 141 of 163 women (86.5\%) preferred vaginal birth, compared to the HIV positive group, where only 19 of the 32 women (59.4\%) preferred a vaginal birth. We found an association between HIV status and mode of delivery that was statistically significant ( $p<$ 0.001). Interestingly, 12 of the women who were HIV positive (37.5) were unsure of their preferred mode of delivery. These women comprised $40 \%$ of the group of women who were unsure of their preference for mode of delivery. In accordance to the South African Antiretroviral Treatment Guidelines of 2013, caesarean section is not offered routinely to women who are HIV positive. ${ }^{38}$ Despite this, the women who are HIV positive and unsure of their preferred mode of delivery, might receive mixed messages about the safety of vaginal birth and might be uncertain about transmission rates to their baby with the different types of delivery.

We found no significant association between level of education ( $p=0.810)$, employment $(\mathrm{p}=0.840)$, level of income $(\mathrm{p}=0.420)$ and relationship status $(\mathrm{p}=$ 0.137 ) and preferred mode of delivery. It is possible that these findings might be different if we had larger study numbers as was evident by Leone et al (2008) who found that women from a higher socio-economic background have better access to antenatal services and are at an increased risk of having a caesarean section. 42

We also found no statistically significant difference in preferred mode of delivery when comparing primigravidas and multigravidas ( $\mathrm{p}=0.185)$. In the primigravid group, $77.0 \%$ preferred vaginal birth, $4.1 \%$ preferred caesarean delivery and $18.9 \%$ were unsure. Of the women in the multiparous group, a higher percentage (85.1\%) preferred vaginal birth, $1.7 \%$ preferred caesarean section and $13.2 \%$ were unsure of their preferred mode of delivery. This 
difference was not significant. These findings are not in keeping with a metaanalysis by Mazzoni et al (2010), which showed a higher preference for caesarean section delivery in multiparous women (17.5\%; CI 13.4 - 21.8). ${ }^{66}$ This could be explained by the fact that we excluded women who had previous pregnancy complications from our study.

The reasons cited by most women in the group preferring vaginal birth were: 'being home sooner' (96.2\%) and the ability to care for their baby better (95.6\%). Other reasons revolved around the perceived safety of vaginal birth for their baby (95.6\%) and themselves (93.7\%). Lastly, $92.1 \%$ of women preferred vaginal birth because 'they wanted a natural birth experience'. Although ranked lower down the list of reasons, a substantial number of women preferred vaginal birth because they were afraid to have an operation and because vaginal birth is less painful (90.0\%). The reason given by the fewest women in this group were, 'not wanting a scar' (79.4\%). These reasons given by the women in our study were similar to a study by Pang et al (2007), although the order of prevalence is slightly different. The reasons given in their study for preferring vaginal delivery were: 'natural way of delivery' (36.3\%), safer for the baby (22.3\%), quicker post delivery recovery (21.3\%), safer for the mother (15.5\%) and less pain (4.2 $\%{ }^{69}$

Only 5 of our participants preferred a caesarean section. The reason for preferring caesarean section to which they all of them agreed was: 'fear to give birth vaginally' (100\%). The WHO recently released a statement regarding disrespect and abuse in labour. They stated that: "Every woman has the right to the highest attainable standard of health, which includes the right to dignified, respectful health care." 79 Although the prevalence of abuse in labour is not known, it might contribute significantly to women's fear of giving birth vaginally. A United States Agency for International Development (USAID) report about disrespect and abuse in childbirth released in 2010, confirms the widespread problem of abuse in labour and emphasizes the negative impact that this might have on women seeking help in health care facilities preventing them from 
accessing care in labour.80 There are also South African studies documenting widespread reports of abuse in labour. Farrel et al (2004) reported that physical abuse of women in labour, is frequently witnessed by medical students doing their training in community obstetrics. ${ }^{81}$ Jewkes et al (1998) conducted a qualitative study exploring the reasons behind abuse in labour. They found that women frequently reported abuse in labour, ranging from physical and verbal abuse, to neglect in labour. Once again, this caused fear and mistrust between the patients and health care providers. ${ }^{82}$

The second reason given by women preferring a caesarean section, was 'a worry about losing bladder and bowel control' (80\%). Of the women preferring caesarean section, $60 \%$ agreed that caesarean delivery was safer for themselves and their baby, less painful than vaginal birth, that they could plan the birth in advance, that they didn't want any vaginal cuts or tears, and that they were concerned about vaginal prolapse. Lastly, only $40 \%$ of these women agreed that their reasons for preferring a caesarean section were those of wanting a sterilization, and better sexual function in the future. In contrast to our findings, Pang et al (2007) reported the most common reason for preferring caesarean section to be the perception that it was safer for the baby. Fear of vaginal birth is listed as the second reason for preferring caesarean section in this study. ${ }^{69}$ Chong et al (2003) reported the top two reasons for wanting a caesarean section in their population to be avoiding labour pain and stress and minimizing the risk of fetal distress and an emergency caesarean section. ${ }^{62}$ These findings are also different from our study.

The Horak study ${ }^{83}$ postulated that the HIV epidemic could be one of the major contributors to the rising caesarean section rates in our population. Interventions such as external cephalic version, artificial rupture of membranes, fetal scalp clip and/ or fetal scalp pH are contraindicated in HIV positive patients, and are ultimately associated with more caesarean sections being performed. Although our study did not investigate the reasons for the rising caesarean 
section rate in South Africa, it did, however, prove that women's preference for caesarean section is unlikely to contribute to the rising caesarean section rates.

We examined women's knowledge about indications for caesarean section. Most women agreed that the following scenarios necessitated a caesarean section: breech presentation (87.7\%), 'when you have small hip bones' (85.6\%) and 'when the baby is big' (80.5 \%). This would be in keeping with standard practice, as breech presentation has become a frequent indication for caesarean delivery, following the findings of the Term Breech Trial. ${ }^{39}$ The three indications for caesarean section that women disagreed with the most, were being HIV positive (86.7\%), a previous caesarean section (80.5\%), and when you ask for a caesarean section (57.4\%). The indication most women were unsure about was twins (31.3\%). Other studies in our literature review did not examine women's knowledge about caesarean section indications. Our study did not explore the source of information used by women regarding the perceived benefits or risks of the different modes of delivery.

Finally, we evaluated women's beliefs about their rights to request a caesarean section. Just over half of women that participated in our study, did not believe that women should be given the right to request a caesarean section (54.4\%). Of the remaining participants, $7.2 \%$ were unsure, and $38.5 \%$ believed that women should have the right to request a caesarean section. This is a surprising finding, considering that in our study the majority of women preferred a vaginal birth. The responses to women's right to request a caesarean section in other studies varied. Bettes et al (2007) reported similar findings to our study, with $54.6 \%$ of participants responding that women should have the right to request a caesarean section. It is important to note, however, that these study participants were all obstetrician and gynaecologist specialists. ${ }^{56}$ Another study reported that smaller groups of women indicated that they should have the right to request a caesarean section. Johanson et al (2000) reported $30 \%$ of patients and $33 \%$ of health care practitioners indicated that women should have the right to have a caesarean section on demand. Chong et al (2003) stated that $71.3 \%$ of their 
study participants felt that women should have the right to demand a caesarean section. ${ }^{62}$

\section{$\underline{\text { Strengths and limitations }}$}

A strength of our study was that we recruited participants at two MOUs, with different ethnic and cultural demographics. This minimized the chance for selection bias. By excluding high-risk pregnancies from our study and specifically women who had a previous caesarean section, we could see the preference in a true low risk population group. We felt that this was important, as it is well known that women with a previous caesarean section might be biased toward caesarean section. However, a potential limitation of concentrating only on a low risk population is that we would not have adequately examined the influence of negative birth experiences in previous complicated pregnancies on women's preferences for mode of delivery in subsequent pregnancies. This could be the subject of future research.

Our sample size was large enough to prove our primary outcome. This left no doubt that in our study population, most women prefer vaginal delivery. The unanticipated small number of women in our study who preferred caesarean delivery (5 out of 195), made it difficult to compare the characteristics of this group, to the group who preferred vaginal delivery (160 out of 195), or to compare the preference of primigravidas and multigravidas as we initially intended to do.

The fact that our questionnaire was conducted by trained interviewers had some benefits in that very few of the questionnaires were spoilt or incomplete. It also had the benefit that the questions that were unclear could be explained to the participants. The interviewers were not health care providers or in any way responsible for the medical care of the participants. This hopefully aided the 
participants to answer the questions freely, without feeling that they could not answer in a certain way. None of the participants, however, gave any response to the open-ended questions. It is possible that this would have been different if the participants completed the questionnaires themselves.

The questionnaires were conducted in the third trimester, but as we observed from other studies, women's preference for mode of delivery might change over time. This could result in their preference for mode of delivery being very different at the time of delivery than for instance, at 32 weeks gestation.

We did not collect any data on what information women based their knowledge regarding indications for caesarean section. Knowing what these sources are might assist in making recommendations regarding patient education and knowledge about perceived benefits and risks of vaginal birth and caesarean section. The importance of having a knowledge of the sources of information on which patients might base their beliefs regarding mode of delivery was emphasized in a Brazilian study by Torloni et al (2011). They evaluated information from women's magazines regarding caesarean section and found that the maternal and perinatal risks that are commonly associated with caesarean delivery, were frequently underrated..$^{84}$

\section{Implications for Further Research}

Following the participants in a longitudinal study and collect data on their actual delivery method and documenting how their birthing experience might influence preferred mode of delivery. This would provide information about negative birth experiences, fear of birth, and anger that might only become apparent in the postpartum period, and enable counselling to address some of these issues.

Further studies are also needed on the long-term risks and benefits of caesarean section. This would provide health care practitioners with better information, 
enabling them to counsel women seeking information about caesarean section on request, in a balanced way, affording them the opportunity to make an informed decision.

\section{$\underline{\text { Recommendations }}$}

We found that a substantial portion of the women in our setting was unsure about their preferred method of delivery, and that most of them were from a low socio-economic background. Based on this finding, we would recommend specific education sessions during the antenatal visits, aimed to inform women about the risks and benefits of vaginal birth and caesarean section.

We also found a significant of women who were HIV positive and unsure of their preferred mode of delivery. This is another possible gap in antenatal education that needs to be addressed. HIV positive women should be counselled during their pregnancy about the benefits of HAART. The likelihood of transmission to the baby with the different modes of delivery should also be addressed during these sessions.

We also found that even though statistically only a small number of women preferred caesarean section, all of them cited fear of vaginal birth as the main reason for their choice. Addressing these fears and exploring the background for the women's perceived fear of vaginal birth during their antenatal visits, will go a long way to help address these issues. We also need to promote more 'respectful maternity care' facilities. Women who are identified to have a pathological fear of birth will also need to be referred for supportive and possibly psychiatric counselling. Unless specifically asked about these fears during their antenatal visits, women might not volunteer this information. 


\section{CONCLUSION}

The need for maternity services that are more women-centred has arisen, with an increasing emphasis on maternal choice and birth satisfaction. The rationale behind this study was to gain better insight into the preferred mode of delivery in a low-risk population, living in Cape Town, as very little is known about this topic in the South African context. Our study contributed to the mounting body of evidence that the majority of women prefer to have a vaginal delivery. There were a considerable number of women in our study population who were unsure about their preference. This indicates a need for improved antenatal education. Although most women preferred a vaginal delivery, more than half of our study participants believed that women should be given the choice of how they wanted their babies to be delivered. Knowledge about women's preference and the reasons they regard as important will aid health care providers in counselling patients appropriately regarding the risks and benefits of both delivery methods and thereby enable women to make an informed decision about their preferred mode of delivery. 


\section{REFERENCES}

1. Menacker F, Hamilton BE. Recent trends in caesarean delivery in the United States. NCHS Data Brief 2010 March; 35:1-8.

2. Arias E, MacDorman F, Strobino DM, Guyer B. Annual summary of vital statistics - 2002. Paediatrics 2003; 112: 1215-30.

3. Betran AP, Merialdi M, Lauer JA, Bing-Shun W, Thomas J, et al. Rates of caesarean section analysis of global, regional and national estimates. Paediatr Perinat Epidemiol 2007; 21: 98-113.

4. Villar J, Valladares E, Woydyla D, Zavaleta N, Carroli G, et al. Caesarean delivery rates and pregnancy outcomes: The 2005 WHO global survey on maternal and perinatal health in Latin America. Lancet 2006; 367: 1819-29.

5. Belizan JM, Althabe F, Cafferata ML. Health Consequences of the Increasing Caesarean Section Rates. Epidemiology 2006; 18(4): 485-486

6. National Institute for Health and Clinical Excellence. Caesarean section clinical guideline 132, November 2011. http://www.guidance.nice.org.uk/CG132 (16 September 2014)

7. World Health Organization. Appropriate technology for birth. Lancet 1985; 2: $436-437$.

8. Thomas J, Paranjothy S. Royal College of Obstetricians and Gynaecologists Clinical Effective Support Unit. The National Sentinel Caesarean Section Audit Report. London: RCOG Press, 2001.

9. Chalmers BE, McIntyre JA, Meyer D. South African obstetricians' views on caesarean section. SAMJ 1992; 82: 161-163.

10. Pevzner L, Goffman D, Freda MC, Dayal AK. Patients' attitudes associated with caesarean delivery on maternal request in an urban population. Am J Obstet Gynecol 2008; 198: e35-37. 
11. Hildingsson I, Radestad I, Rubertsson C, Waldernstrom U. Few women wish to be delivered by caesarean section. BJOG 2002; 109(6): 618-623.

12. McCourt C, Weaver J, Statham H, Beake S, Gamble J, et al. Elective caesarean section and decision making: A critical review of the literature. Birth 2007; 34: 65-79.

13. Robson MS. Can we reduce the caesarean section rate? Best Practice and Research. Clin Obstet Gynaecol 2001; 15(1): 179-194.

14. Lee SI, Khang YH, Lee MS. Women's attitudes toward mode of delivery in South Korea - a Society with high Caesarean Section rates. Birth 2004; 31(2): 108-116

15. World Health Statistics 2006

http://www.who.int/gho/publications/world_health_statistics/whostat2006_er ratareduce.pdf (17 September 2014)

16. Day C, Gray A. Health and related indicators. In: Padarath A, English R, editors. South African Health Review 2012/13. Durban: Health Systems Trust; 2013.

URL: http://www.hst.org.za/publications/south-african-health-review-2012/13

17. Tshibangu KC, de Jongh MA, de Villiers DJ, du Toit JJ, Shah SMH. Incidence and outcome of caesarean section in the private sector - 3 year experience at Pretoria Gynaecological Hospital. SAMJ 2002: 92(12); 956-959.

18. Althabe F, Sosa C, Belizán JM, Gibbons L, Jacquerioz F, et al. Caesarean Section Rates and Maternal and Neonatal Mortality in low-, medium-, and highincome countries: An Ecological Study. Birth 2006; 33(4): 270-277.

19. National Institutes of Health. State-of-the-Science-Conference: Cesarean delivery on maternal request: final statement. Obstet Gynecol 2006; 107:13861395. 
20. Sewell JE. Cesarean Section - A Brief History. A Brochure to accompany the History of Cesarean Section at the National Library of Medicine.

www.nlm.nih.gov/hmd/pdf/cesaran.pdf (16 September 2014)

21. Todman D. A history of caesarean section: From ancient world to the modern era. Aust N Z J Obstet Gynaecol 2007; 47(5): 357-361.

22. Reiss H. Abdominal delivery in the $16^{\text {th }}$ century. J Royal Soc Med 2003; 96 : 370.

23. Munro Kerr JM, ed. Historical Review of British Obstetrics and Gynaecology. London: E \& S Livingstone, 1954

24. Villar J, Garroli G, Zavaleta N, Donner A, Woydyla D, et al. Maternal and neonatal individual risks and benefits associated with caesarean delivery: Multicentre prospective study. BMJ 2007; 335 (7628): 1025-1036.

25. Souza JP, Gülmezoglu AM, Lumbiaganon P, Laopaiboon M, Carolli G, et al. Caesarean section without medical indications is associated with an increased risk of adverse short-term maternal outcomes: The 2004-2008 WHO Global Survey on Maternal and Perinatal Health. BMC Medicine 2010; 8(1): 71.

26. Kandasamy T, Merialdi M, Guidotti R, Betrán A, Harris-Requejo J, et al. Cesarean delivery surveillance system at a maternity hospital in Kabul, Afghanistan. Int J Gynecol Obstet 2009; 104: 14-17.

27. Shah A, Fawole B, Machoki M'Imunya J, Amokrane F, Nafiou I et al. Cesarean delivery outcomes from the WHO global survey on maternal and perinatal health in Africa. Int J Gynecol Obstet 2009, doi: 10.1016/j.ijgo.2009.08.013

28. Aziken M, Omo-Aghoja L, Okonofua F. Perceptions and attitudes of pregnant women towards caesarean section in urban Nigeria. Acta Obstet Gynaecol 2007; 86: $42-27$. 
29. Brown E, Carroll J, Fogarty C, Holt C. "They get a C-Section..They gonna die": Somali Women's fears of Obstetrical Interventions in the United States. J Transcult Nurs 2010; 21: 220- 227.

30. Fogelson NS, Menard MK, Hulsey T, Ebeling HTBE. Neonatal impact of elective repeat cesarean delivery at term: A comment on patient choice cesarean delivery. Am J Obstet Gynecol 2005; 192: 1433-1436.

31. Sultan AH, Kamm MA, Hudson CN, Thomas JM, Bartram CI. Anal-sphincter disruption during vaginal delivery. N Engl J Med 1993; 329: 1905-1911.

32. Nelson RL, Westercamp M, Furner S. A Systematic Review of the efficacy of Cesarean Section in the preservation of anal continence. Dis Colon Rectum 2006; 49(10): 1587-1595.

33. Belizán JM, Cafferata ML, Althabe F. Risks of patient choice caesarean. Birth 2006; 33(2): 167-169.

34. Varma R, Gupta JK, Smith GCS. Birth after previous caesarean birth. RCOG Green-top Guideline No. 45. London: RCOG Press, 2007.

35. Fournier F, Dumont A, Tourigny C, Dunkely G, Drame, et al. Improved access to comprehensive emergency obstetric care and its effect on institutional maternal mortality in rural Mali. Bull world Health Organ 2009: 87: 30-38.

36. Mode of delivery in HIV-infected pregnant women and prevention of mother-to-child transmission: Changing practices in Western Europe. HIV Medicine [serial on the Internet]; 2010, July 11(6): 368-378. Available from: Academic Search Premier.

37. Low-Beer NM, Penn ZJ. Management of HIV in pregnancy. RCOG Green-top guideline no. 39. London: RCOG Press, 2010.

38. Department of Health. The South African Antiretroviral Treatment Guidelines, 2013. 
www.hst.org.za/publications/pmtct-guidelines-2013 (17 September 2014)

39. Hannah ME, Hannah WJ, Hodnett ED, Chalmers B, Kung R et. al. Outcomes at 3 months after planned Cesarean vs. planned Vaginal delivery for breech presentation at Term. JAMA 2002; 287(14): 1822-1831.

40. Al-Mufti R, McCarthy A, Fisk NM. Obstetricians' personal choice and mode of delivery. The Lancet 1996; 347(9000): 544 .

41. Wu J, Hundley A, Visco AG. Elective Primary Cesarean Delivery: attitudes of Urogynecology and Maternal-Fetal Medicine Specialists. Obstet Gynecol 2005; 105:301-306.

42. Leone $\mathrm{T}$, Padmadas $\mathrm{S}$, Matthews $\mathrm{Z}$. Community factors affecting rising caesarean section rates in developing countries: An analysis of six countries. Social Science \& Medicine 2008; 67: 1236-1246.

43. Faisal-Cury A, Menezes PR. Factors associated with preference for cesarean delivery. Rev Saude Publica 2006; 40(2): 226-232.

44. Dodd J, Pearce E, Crowther C. Women's experiences and preferences following Caesarean birth. Aust N Z J Obstet Gynaecol 2004; 44: 521-524.

45. Belizán JM, Althabe F, Barros FC, Alexander S. Rates and implications of caesarean section in Latin America: Ecological study. BMJ 1999; 319: 13971400.

46. Murray S. Relation between private health insurance and high rates of caesarean section in Chile: Qualitative and quantitative study. BMJ 2000; 321: 1501-1505.

47. Lawrie TA, de Jager M, Hofmeyr GJ. Int J Gynecol Obstet 2001; 2: 71-73.

48. Jackson NV, Irvine LM. The influence of maternal request on the elective caesarean section rate. J Obstet Gynaecol 1998; 18(2): 155-119. 
49. Wilkinson C, Turnbull D. Decision Making for caesarean section. Use of Computerised Operation Notes to Audit Clinical Practice: The role of Patient Autonomy. Abstracts of the 4th Congress of the Perinatal Society of Australia and New Zealand Alice Springs (A154). 1998.

50. Quinlivan JA, Petersen RW, Nichols CN. Patient preference the leading indication for elective caesarean section in public patients - Results of a 2-year Prospective Audit in a Teaching Hospital. Aust NZ J Obstet Gynaecol 1999; 39: 207- 214.

51. Gossman GL, Joesch JM, Tanfer K. Trends in maternal request cesarean delivery from 1991 to 2004 . J Obstet Gynecol 2006; 108(6): 1506-1516.

52. Wax JR, Cartin A, Pinette MG, Blackstone JB. Patient choice cesarean: An evidence based review. Obstet Gynecol Surv 2004; 59(8): 601-616.

53. Wiklund I, Edman G, Ryding E, Andolf E. Expectation and experiences of childbirth in primiparae with caesarean section. BJOG 2008; 115:324-331.

54. Rouhe H, Slamela-Aro K, Halmesmäki E, Saisto T. Fear of childbirth according to parity, gestational age, and obstetric history. BJOG 2009; 116:6773.

55. Gamble RM, Creedy RN, McCourt C, Weaver J, Beake S. A Critique of the literature on women's request for cesarean section. Birth 2007; 34: 331-340.

56. Bettes BA, Coleman V, Zinberg S, Spong CY, Portnoy B, et al. Cesarean delivery on maternal request. Obstet Gynecol 2007; 109(1): 57-66.

57. FIGO Committee Report. FIGO committee for the ethical aspects of human reproduction and women's health. Int J Obstet Gynecol 1999; 64: 317-332.

58. Operative vaginal delivery. ACOG Practice Bulletin No. 17. American College of Obstetricians and Gynecologists. June 2000. 
59. Cotzias CS, Paterson-Brown S. Fisk NM. Obstetricians say yes to maternal request for elective caesarean section: A survey of current opinion. Eur J Obstet Gynecol Reprod Biol 2001; 97: 15-16.

60. Bergholt T, Østberg B, Legarth J, Weber T. Danish obstetricians' personal preference and general attitude to elective cesarean section on maternal request: A nation-wide postal survey. Acta Obstet Gynecol Scand 2004; 83: 262-266.

61. Tranquilli AL, Garzetti GG. A new ethical and clinical dilemma in obstetric practice: Cesarean section "on maternal request". Am J Obstet Gynecol 1997; 177: $245-246$.

62. Chong ESY, Mongelli M. Attitudes of Singapore women toward cesarean and vaginal deliveries. Int J Gynecol Obstet 2003; 80: 189-194.

63. Johanson RB, El-Timini S, Rigby C, Young P, Jones P. Caesarean section by choice could fulfil the inverse care law. Eur J Obstet Gynecol Reprod Biol 2000; 97: 20-22.

64. Pakenham S, Chamberlain SM, Smith GN. Women's views on elective primary caesarean section. J Obstet Gynaecol Can 2006; 28: 1089-1094.

65. Manthata ALA, Hall DR, Steyn PS, Grové. The attitudes of two groups of South African women towards mode of delivery. Int J Gynecol Obstet 2006; 92 : 87-91.

66. Mazzoni A, Althabe F, Liu NH, Bonotti AM, Gibbons L, et al. Women's preference for caesarean section: A systematic review and meta-analysis of observational studies. BJOG 2011; 118: 391-399.

67. Angeja ACE, Washington AE, Vargas JE, Gomez R, Rojas I, et al. Chilean women's preferences regarding mode of delivery: Which do they prefer and why? BJOG 2006; 113: 1253-1258.

68. Gamble JA, Health M, Creedy DK. Women's preference for a cesarean section: incidence and associated factors. Birth 2001; 28(2): 101-110. 
69. Pang SMW, Leung DTN, Leung TY, Lai CY, Lau TK, et al. Determinants of preference for elective caesarean section in Hong Kong Chinese pregnant women. Hong Kong Med J 2007; 13(2): 100-105.

70. Mancuso A, De Vivo A, Fanara G, Settineri S, Triolo 0, et al. Women's preference on mode of delivery in Southern Italy. Acta Obstet Gynecol 2006; 85: 694-699.

71. Kingdon C, Neilson J, Singleton V, Gyte G, Hart A, et al. Choice and birth method: Mixed-method study of caesarean delivery for maternal request. BJOG 2009; 116: 886-895.

72. Pang MW, Lee TS, Leung AKL, Leung TY, Lau TK, et al. A longitudinal observational study of preference for elective caesarean section among nulliparous Hong Kong Chinese women. BJOG 2007; 114: 623-629.

73. Lee SI. Khang YH, Lee MS. Women's attitudes toward mode of delivery in South Korea, a society with high cesarean section rates. Birth 2004; 31: 108116.

74.http://www.doh.gov.za/docs/reports/2012/Report_on_Confidential_Enquiri es_into_Maternal_Deaths_in_South_Africa.pdf (19 September 2014)

75. A Population profile of Mitchell's Plain: Socio-economic information from the 2001 Census. Information and Knowledge Department. Oct. 2005

76. Statistics South Africa. Census 2001.

www.statssa.gov.za/census01/html/RSAPrimary.pdf (19 September 2014)

77. Liu NH, Mazzoni A, Zamberlin N, Colomar M, Chang OH et al. Preferences for mode of delivery in nulliparous Argentinean women: a qualitative study. Reprod Health 2013; 10(1): 1-7.

78. WMA News: Revising the Declaration of Helsinki. World Medical Journal 2008; 54(4): 120-125 
79. World Health Organization. "The prevention and elimination of disrespect and abuse during facility-based childbirth: WHO statement." (2014).

http://www.who.int/iris/handle/10665/134588 ( 17 September 2014)

80. Browser D, Hill K. Exploring evidence for disrespect and abuse in facilitybased childbirth. USAID-TRAction Project, Harvard School of Public Health (2010).

81. Farrel E, Pattinson RC. Out of the mouths of babes - innocent reporting of harmful labour ward practices. SAMJ 2004; 94 (11): 896 - 897.

82. Jewkes, R, Abrahams N, Mvo Z. Why do nurses abuse patients? Reflections from South African Obstetric Services. Soc Sci Med 1998; 47 (11): 1781 - 1795.

83. Horak A: An Analysis of the Caesarean Section Rate at Mowbray Maternity Hospital Using Robson's Ten Group Classification System. MMed in Obstetrics and Gynaecology, submitted to the University of Cape Town, 2013

84. Torloni MR, Daher S, Betrán AP, Widmer M, Montilla P et al. Portrayal of caesarean section in Brazilian women's magazines: 20 year review. BMJ 2011; 342: d276. 


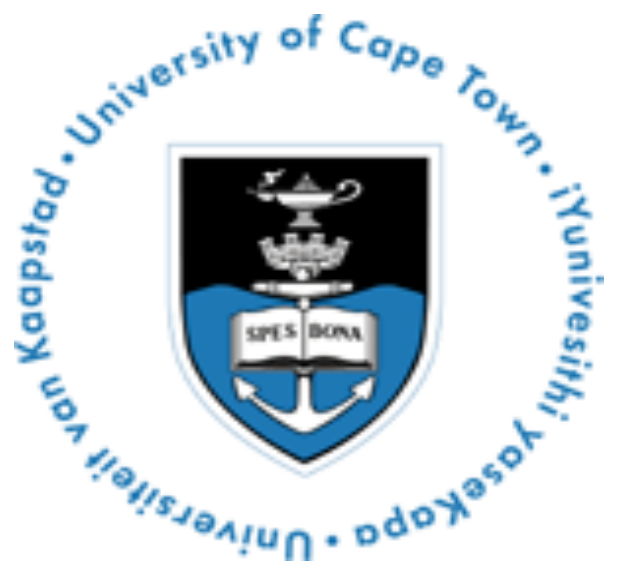

Appendix 
Appendix A - Questionnaire

UNIVERSITY OF CAPE TOWN

IYUNIVESITHI YASEKAPA * UNIVERSITEIT VAN KAAPSTAD

\section{WOMEN'S PREFERENCE FOR MODE OF DELIVERY IN CAPE TOWN QUESTIONNAIRE}

HREC REF: $398 / 2013$

Patient study number

Date of interview

Place of interview

Interviewer

Note: All questions will be expressed in a language which the participant understands

\section{A. SOCIO-DEMOGRAPHIC CHARACTERISTICS}

1. How old are you? years

2. Ethnicity?

1= Black African

$2=$ Coloured

$3=$ White

$4=$ Indian

$5=$ other (please specify) 
3. Home language?

1= English

$2=$ Xhosa

$3=$ Afrikaans

$4=$ other (please specify)

4. What is your nationality?

$1=$ South African

$2=$ other (please specify)

5. What is your highest level of education?

1= Primary school incomplete

$2=$ Primary school complete

$3=$ High school incomplete

$4=$ High school complete

$5=$ Tertiary

6. Do you have a job?

$1=$ Yes (go to question 7)

$2=$ No (go to question 9)

7. How much do you get paid in a month?

$1=<\mathrm{R} 3000$

$2=\mathrm{R} 3000-\mathrm{R} 10000$

$3=>\mathrm{R} 10000$

8. Are you a health care professional?

$1=$ Yes

$2=\mathrm{No}$

9. What are the walls of your home made of?

$1=$ Brick/cement/concrete

$2=$ Wood 
$3=$ Corrugated iron $/$ tin

$4=$ other (please specify)

10. Where do you get your water from?

$1=$ Running water indoors from tap

$2=$ Outdoor tap only

$3=$ Public or communal tap

$4=$ Water tank/container

$5=$ Borehole

6= Dam/river

$7=$ other (please specify)

11. What kind of toilet do you have?

$1=$ Indoor flushing toilet

$2=$ Outdoor flushing toilet

$3=$ "Long drop" /Pit toilet

$4=$ Bucket

$5=$ None

12. Are you in a relationship?

$1=$ Yes (go to question 13)

$2=$ No (go to question 14)

13. What kind of relationship are you in?

$1=$ Steady boyfriend (not co-habiting)

$2=$ Steady boyfriend (co-habiting)

$3=$ Married

$4=$ Divorced

$5=$ Widowed

14. Do you smoke?

$1=$ Yes

$2=\mathrm{No}$ 
15. Do you use alcohol?

$1=$ Yes

$2=\mathrm{No}$

\section{SECTION B: OBSTETRIC HISTORY}

16. How far are you pregnant?

weeks

17. Is this your first pregnancy?

$1=$ yes (go to question 27)

$2=$ no (go to question 18)

18. How many times have you been pregnant?

(This pregnancy included)

$$
\begin{aligned}
& 1=2 \text { times } \\
& 2=3 \text { times } \\
& 3=4 \text { times } \\
& 4=5 \text { times or more }
\end{aligned}
$$

19. How many live births have you had before?

$$
\begin{aligned}
& 1=1 \text { live births } \\
& 2=2 \text { live births } \\
& 3=3 \text { live births } \\
& 4=4 \text { live births } \\
& 5=5 \text { or more live births }
\end{aligned}
$$

20. Have you had a miscarriage?

1= yes (if yes, how many?)

Miscarriages

$2=$ no

21. Have you had an ectopic pregnancy?

$1=$ yes (if yes, how many?)

Ectopics

$2=$ no 
22. Have you had a termination of pregnancy?

$1=$ yes (if yes, how many?)

TOP's

$2=$ no

23. Have you had a vaginal delivery previously?

$1=$ yes (if yes, how many?)

NVD's

$2=$ no

24. Have you had an instrumental delivery previously?

(Forceps or vacuum)

1=yes (if yes, how many?)

Instrumental Deliveries

$2=$ no

25. Have any of your babies been admitted to ICU after birth?

$1=$ yes
$2=$ no

26. Is this a planned pregnancy?

$1=$ yes

$2=$ no

$3=$ unsure

27. What is your HIV status?

$1=$ positive
$2=$ negative
$3=$ unsure
$4=$ not tested 


\section{SECTION C: PREFERENCES AND PERCEPTIONS ABOUT MODE OF DELIVERY}

28. If you could choose, how would you like your baby to be delivered?

$1=$ vaginal delivery (answer question 29, 31 and 32)

$2=$ caesarean section (answer question 30, 31 and 32)

$3=$ unsure (answer question 31 and 32)

29. I would prefer a vaginal birth because....

(Every question must be answered)

\begin{tabular}{|l|l|l|l|}
\hline & $1=y e s$ & $2=$ no & $\begin{array}{l}3=\text { not } \\
\text { sure }\end{array}$ \\
\hline It is safer for me & & & \\
\hline It is safer for my baby & & & \\
\hline I am afraid to have an operation & & & \\
\hline It will not be as painful as an operation & & & \\
\hline I want a 'natural' birth experience & & & \\
\hline I do not want a scar & & & \\
\hline I will be able to care for my baby better & & & \\
\hline I will be able to breastfeed sooner & & & \\
\hline I will be home sooner & & & \\
\hline Other: Please specify & & & \\
& & & \\
\end{tabular}


30. I would prefer a caesarean section because....

(Every question must be answered)

\begin{tabular}{|c|c|c|c|}
\hline & $1=$ yes & $2=$ no & $\begin{array}{l}3=\text { not } \\
\text { sure }\end{array}$ \\
\hline It is safer for me & & & \\
\hline It is safer for my baby & & & \\
\hline I am afraid to give birth vaginally & & & \\
\hline I had a caesarean section previously & & & \\
\hline It is not as painful as giving birth vaginally & & & \\
\hline I can plan when the baby will be born & & & \\
\hline I want a sterilization & & & \\
\hline I don't want tears or cuts to my vagina & & & \\
\hline $\begin{array}{l}\text { I am worried that I won't be able to control } \\
\text { my bladder or bowel in future }\end{array}$ & & & \\
\hline $\begin{array}{l}\text { I am worried that I will have a vaginal } \\
\text { prolapse in future }\end{array}$ & & & \\
\hline $\begin{array}{l}\text { I think it is better for my future sexual } \\
\text { function }\end{array}$ & & & \\
\hline Other: Please specify & & & \\
\hline
\end{tabular}

31. Do you think a caesarean section is necessary in the following cases? (All participants to answer)

\begin{tabular}{|l|l|l|l|}
\hline & $1=$ yes & $2=$ no & $\begin{array}{l}3=\text { not } \\
\text { sure }\end{array}$ \\
\hline If the baby is a breech presentation & & & \\
\hline When you've had a caesarean section before & & & \\
\hline If the baby is very big & & & \\
\hline When your hip bones are too small & & & \\
\hline $\begin{array}{l}\text { When the baby is not yet born after your due } \\
\text { date }\end{array}$ & & & \\
\hline If you have a twin pregnancy & & & \\
\hline If you are HIV positive & & & \\
\hline When you ask for a caesarean section & & & \\
\hline Other: Please specify & & \\
& & \\
\end{tabular}


32. Do you think women should be able to choose how their babies should be delivered?

$$
\begin{aligned}
& 1=\text { Yes } \\
& 2=\text { No } \\
& 3=\text { Unsure }
\end{aligned}
$$

Thank you very much for participating in this study 


\title{
Appendix B - Patient information leaflet and consent form
}

\author{
UNIVERSITY OF CAPE TOWN \\ IYUNIVESITHI YASEKAPA • UNIVERSITEIT YAN KAAPSTAO

\section{Women's preference for mode of delivery: Information leaflet}

\section{HREC REF: $398 / 2013$}

\section{Introduction}

You are invited to take part in a research study. Participation in this study is completely voluntary and you may choose to withdraw at any time. This leaflet will give you information about why the study is being done, who can take part in it, as well as any risks and benefit to you.

You will be asked to answer a questionnaire with the help of an interviewer. The questions will be about your social circumstances, work and housing. You will also be asked which way you think is the best to deliver your baby and why. Should there be anything you don't understand we will take time to explain any questions you might have. We will also collect data on the way in which you gave birth after your delivery.

\section{STUDY TITLE}

Women's preference for mode of delivery in Cape Town

\section{RESEARCHERS}

Dr Nadia Naude

Dr Tracey Anne Horak

Prof Susan Fawcus

The study has been approved by the Human Research Ethics Committee of the Faculty of Health Sciences of the University of Cape Town. If you would like any further information, please feel free to contact us. After reading this information leaflet you will be asked to sign an informed consent form to take part in the study. You will also be given a copy of this consent form 


\section{Why is this study being done?}

There are very few South African studies about women's preference for mode of delivery. Caesarean section on demand is not offered routinely in the state health sector in South Africa. There is ongoing debate in obstetrics whether this should be an option open to women. Doing this study would provide us with information in which manner women would prefer to give birth if given a choice and why. We hope that the information gained will improve obstetric services in future with the focus shifting towards better birthing experiences and patient satisfaction.

\section{Study participants}

- Any women 18 years and older attending antenatal care for a low risk pregnancy in their $3^{\text {rd }}$ trimester (from 32 weeks) at Gugulethu and Mitchell's Plain is invited to take part in this study.

- Participation in this study is completely voluntary and you can choose to opt out at any time.

- To be part of the study we will ask you to complete a questionnaire by a trained interviewer in a language of your choice. This should take 20 minutes

- If you do not wish to answer any of the questions, you may skip them.

- If you don't understand any question, we will take time to explain it to you.

- Not choosing to participate in the study or opting out during the study will not impact on the health care that you are receiving in any way.

\section{Risks}

This study involves a questionnaire we will collect information on your actual mode of delivery after you have given birth and will not pose any risk to you.

\section{Benefits}

There is no financial reward in taking part in this study. You may not benefit directly from taking part in this study, but providing us with this information you will assist us in finding out in which way women would prefer to give birth. 


\section{Confidentiality}

- The questionnaire will be completed in a private area

- The questionnaire will have a number on it instead of your name. Only the researchers will know what your number is and this information will be kept in a secure office in Mowbray Maternity Hospital.

- Only the researchers will have access to the completed questionnaires and research data

- When the study is completed the research data will be stored in the Department of Obstetrics and Gynaecology of the University of Cape Town.

- This research forms part of work towards a Masters degree at the University of Cape Town and will be submitted for examination within the university. The results of this study will be anonymous and you will not be identified in any results.

- You will be asked to sign a consent form for yourself.

\section{Contact information}

If you have any further questions, comments or queries regarding this study please feel free to contact Dr N Naude (Principal investigator) at 0823770041.

If you need any further information regarding your rights as a research participant, you can contact the Faculty of Health Sciences Human Research Ethics Committee at (021) 4066338.

Thank you for your time 


\title{
Women's preference for mode of delivery: Consent form
}

\author{
HREC REF: $398 / 2013$
}

I have agreed to participate in a research study about women's preference for mode of delivery. This study is being conducted by members of the Department of Obstetrics and Gynaecology. The study has been approved they the Faculty of Health Sciences Research Ethics Committee of the University of Cape Town. The purpose of this study has been explained to me in a language of my choice by a member of the research team.

I understand the study involves the completion of a questionnaire with the help of a trained interviewer in one of three languages of my choice (isiXhosa/English/Afrikaans). My participation is voluntary and I have the right to withdraw from this study at any stage. I may choose not to answer any question if I so wish. It has been explained to me that this will not affect my medical care and that the study poses no risk to me.

I understand that I may not benefit directly from this study and that there is no financial reward for taking part in this study but that the information collected may benefit other pregnant women in future. I understand that my actual mode of delivery will be determined by whether I have any medical or childbirth complications, which require me to have a caesarean section, in accordance with current practice in Metro West and the South African public sector.

I agree to my responses being used for education and research. It has been explained to me that confidentiality will be maintained where possible and that I will not be personally identifiable in the database or any manuscripts that may subsequently be produced for publication. 
I have been given adequate opportunity to ask questions about this study and have been provided with an information leaflet about the study as well as a copy of the informed consent form. I have read this consent form and the information it contains and had the opportunity to ask questions about them

NAME OF PARTICIPANT

NAME OF INVESTIGATOR

DATE:
SIGNATURE

SIGNATURE 